\title{
Highly Conductive and Strong CuSn0.3 Alloy Processed via Laser Powder Bed Fusion Starting from a Tin-coated Copper Powder
}

\author{
Suraj Dinkar Jadhav a *, Dongmei Fu ${ }^{\text {a }}$, Maxim Deprez ${ }^{\text {a }}$, Kristof Ramharter ${ }^{\text {b }}$, Denise Willems ${ }^{\text {b }}$, \\ Brecht Van Hooreweder ${ }^{\mathrm{c}}$, Kim Vanmeensel ${ }^{\mathrm{a}}$ \\ ${ }^{a}$ KU Leuven, Department of Materials Engineering, Kasteelpark Arenberg 44, B-3001 Heverlee, \\ Belgium \\ ${ }^{\mathrm{b}}$ Aurubis Belgium SA/NV, Watertorenstraat 35, B-2250 Olen, Belgium \\ ${ }^{\mathrm{c}}$ KU Leuven, Department of Mechanical Engineering \& Member of Flanders Make, Celestijnenlaan \\ 300, B-3001 Heverlee, Belgium
}

* Corresponding author: E-mail address: suraj.jadhav@kuleuven.be

Keywords: Powder surface modification; Sn-coated Cu; Laser powder bed fusion; Selective laser melting; Copper reflectivity

\begin{abstract}
Despite the high demand, the successful fabrication of fully dense, highly conductive, and strong copper components via laser powder bed fusion (LPBF) is not readily evident. This is mainly due to the low optical absorption of copper, which inhibits the complete melting of copper powders when using commercially available fiber-laser-based LPBF machines. Accordingly, this article proposes a novel approach of using optically absorptive metal-coated copper powders for the fabrication of fully dense, highly conductive, and strong copper components via LPBF. To validate this approach, the surface of the copper powder is modified by applying a very thin $(62 \pm 14 \mathrm{~nm})$ layer of metallic tin via an immersion plating technique. The application of only a $0.28 \mathrm{wt} \%$ of metallic tin coating significantly improved the room temperature powder optical absorption by $\sim 170 \%$ at the fiber laser wavelength. Consequently, crack-free and fully dense copper parts combining high thermal conductivity of $334 \pm 4 \mathrm{~W} /(\mathrm{m} \cdot \mathrm{K})$ and electrical conductivity of $80 \pm 1 \%$ international annealed copper standard (\%IACS) with a good tensile strength of $256 \pm 14 \mathrm{MPa}$, yield strength of $203 \pm 4 \mathrm{MPa}$, and ductility of $21 \pm 2 \%$ have been fabricated using a fiber laser with an output laser power of $500 \mathrm{~W}$.

Furthermore, the article also describes the negative influence of the presence of a high amount of $(0.091 \mathrm{wt} \%)$ sulfur, which originates from the organic additives during sub-optimal coating conditions, on the LPBF processing behavior of CuSn alloys. As such, high sulfur-containing tin-coated copper powders do not allow the fabrication of fully dense parts due to the occurrence of solidification cracks and the formation of pores. Subsequently, the optimum tin coating methodology, which limits the amount of sulfur below $0.0025 \mathrm{wt} \%$, is described. The use of sulfur-free powder is recommended for the successful LPBF processing of fully dense parts made of copper and copper alloys.
\end{abstract}




\section{Introduction}

The intrinsic high thermal $(400 \mathrm{~W} /(\mathrm{m} \cdot \mathrm{K}))$ and electrical (100\% IACS) conductivity of pure copper along with abundant reserves and low cost makes it the ideal material for manufacturing of heat transfer and electrical components, such as heat exchangers, heat sinks, and windings in electrical machines [13]. However, copper in its pure form is soft; therefore, its use in structural components is rather limited. To broaden the usability of copper in structural components, it is generally alloyed with elements, such as tin, nickel, and chromium. The addition of these alloying elements has a positive influence on mechanical properties; however, alloying drastically reduces the thermal and electrical conductivity of the resulting copper alloy. Therefore, it is essential to limit the amount of alloying elements to the lowest possible level while maintaining acceptable mechanical properties $[4,5]$.

Conventionally, copper and its alloy parts are manufactured mainly using subtractive manufacturing techniques, which require excessive material removal. These techniques not only suffer from material waste but also have a limitation on the achievable geometrical complexity and feature size. This restricts the potential of improving the heat or electricity transfer efficiency of thermal management or electrical components, respectively [6]. Accordingly, there is a need for a manufacturing process that overcomes these limitations. In this regard, laser powder bed fusion (LPBF), also known as selective laser melting (SLM), has been emerging as one of the most promising laserbased additive manufacturing (AM) processes that allows the fabrication of parts with an unimaginable geometrical complexity compared to the conventional manufacturing techniques. Moreover, other advantages such as low material wastage, digital process chain, and low cost to complexity ratio make LPBF an even more interesting process for the manufacturing of heat transfer or electrical components [7,8]. Despite such a huge potential, LPBF of highly conductive copper and its alloys is still underexplored. This is a result of the very high optical reflectivity of copper within the infrared region and the high thermal conductivity [9]. The former characteristic hinders the transfer of laser energy to copper for melting, while the latter allows quick dissipation of the absorbed (heat) laser energy. Accordingly, the complete fusion of copper powder particles, forming fully dense parts, cannot be achieved using the commercially available LPBF machines which are generally equipped with fiber lasers $(\lambda=1070 \pm 10 \mathrm{~nm})$ having output powers up to $400 \mathrm{~W}$ [10-13].

Currently, the efforts to fabricate fully dense copper parts using LPBF are mainly following two strategies: (a) Modification of the laser and (b) Modification of the copper powder. Within the former strategy, researchers are working either on changing the wavelength of the laser source or increasing the laser power output to $1 \mathrm{~kW}$. Changing the laser wavelength from the infrared region (fiber laser $\lambda=$

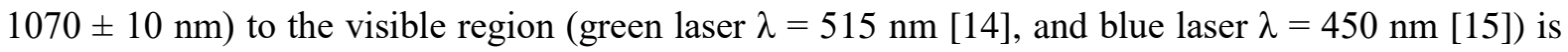
inspired by the low optical reflectivity of copper for the visible radiation. Although fully dense copper parts could be manufactured using green or blue lasers via other laser-based AM processes [16-18], researchers have not yet disclosed the density, mechanical, electrical, or thermal properties of such LPBF fabricated parts. Moreover, the newly developed green or blue laser technology is costly and still in the research phase. On the other hand, the fiber laser technology is well-known, and it has been successfully applied for the processing of various metallic materials (Ti-, Al-, Fe-based alloys). Furthermore, the technological know-how on the interaction between a fiber laser and metal has been widely studied within both laser-based welding and AM processes [7,19,20]. Consequently, other research groups have chosen to continue working with conventionally used fiber lasers, but updating them with a high output power of $1 \mathrm{~kW}$. Both Jadhav et al. [21] and Ikeshoji et al. [22] have used a high laser power of $800 \mathrm{~W}$ in combination with low laser scan speeds of $200-400 \mathrm{~mm} / \mathrm{s}$, whereas Colopi et al. [23] have used multi-pass re-melting at high laser powers of $600-1000 \mathrm{~W}$ and high scan speeds of $1000-3000 \mathrm{~mm} / \mathrm{s}$, as strategies to manufacture fully dense copper parts. During these experiments; however, Jadhav et al. [21] noticed damages to the optical mirrors of the LPBF machine, and the authors 
suggested to avoid the use of high laser powers to process reflective metals, such as copper, silver, and gold, over the safety concerns caused by sustained laser back-reflections.

Within the latter strategy, i.e., modification of the copper powder, researchers mainly aim at improving the powder optical absorption at the fiber laser wavelength with a minimum negative impact on the electrical and thermal conductivity. Besides, few studies were undertaken to enhance densification by using a finer particle size distribution (PSD) and/or a thinner powder bed thickness [24,25]. The improvement in the powder optical absorption can be done either by pre-alloying copper with other metals such as chromium, zirconium, and zinc [26-30], or through surface modification of the copper powder [31,32]. In order to increase the optical absorption of the copper powder up to the level of other LPBF processable alloy powders, a high amount of pre-alloying with laser absorptive metals is required. Accordingly, copper powders have been pre-alloyed with a large amount of laser absorptive alloying elements, and (rather) dense parts have been fabricated using GRCop-84 [33,34], CuSn4 [35,36], CuSn10 [37], CuZn10 [30], and CuSn15 [38] alloys via LPBF. However, the fabricated parts in the as-built condition demonstrated low thermal and electrical conductivity values due to the presence of an excessive amount of alloying elements in solid solution with copper. In contrast, surface modification of copper powder realized via surface oxidation [31], or by the addition of < $0.1 \mathrm{wt} \%$ carbon nanoparticles [5,39] revealed substantial improvements in the powder optical absorption at the fiber laser wavelength. Although both surface modification approaches resulted in a substantial enhancement in the optical absorption of copper powders at room temperature, only the surfaceoxidized copper powder allowed the fabrication of dense copper parts at reduced laser power or volumetric laser energy density compared to the pure copper powder. The inability of the carbon-mixed copper powder to provide a high optical absorption during the actual (real-time) LPBF process has been attributed to the segregation of carbon nanoparticles along the melt pool boundary. This carbon segregation was favored by the poor wettability of solid carbon with liquid copper and the poor bonding of the carbon nanoparticles on the surface of copper powder particles [39]. Both the aforementioned powder surface modification approaches reveal that dense copper parts with high conductivity could potentially be fabricated using lower volumetric energy density values (i.e., at lower laser power and/or higher scan speed); if the surface of the copper powder is modified by the application of a coating material that mixes well with or is wetted well by liquid copper and that exhibits a high optical absorption at the fiber laser wavelength.

Accordingly, the current investigation explores the use of tin-coated copper powders for the successful manufacturing of fully dense, highly conductive, and strong copper parts via the fiber laserbased LPBF process.

\section{Materials and Methods}

\subsection{Virgin Powder}

99.95\% pure, argon atomized, and highly conductive copper $(\mathrm{HC} \mathrm{Cu})$ powder with a D10 of 22.7 $\mu \mathrm{m}, \mathrm{D} 50$ of $34.8 \mu \mathrm{m}$, and D90 of $47.1 \mu \mathrm{m}$ was procured from Sandvik Osprey Ltd., UK. The powder particle size distribution (PSD) was measured in dry mode using the vertical module of a laser diffractometric particle size analyzer LS 13320 by Beckman Coulter, and the PSD result is plotted in Figure 1. 


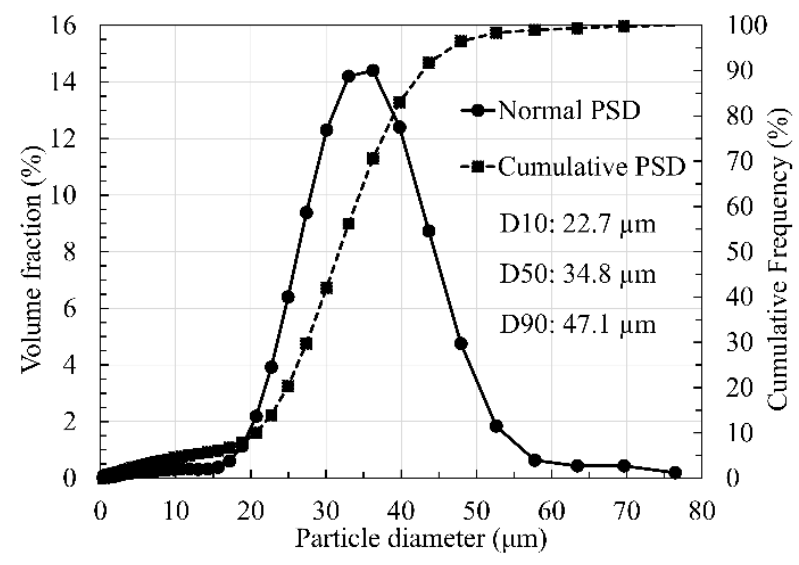

Figure 1: Particle size distribution (PSD) of the pure copper powder before the application of a tin coating.

\subsection{Immersion Plating Method and Characterization of Tin-coated Copper Powders}

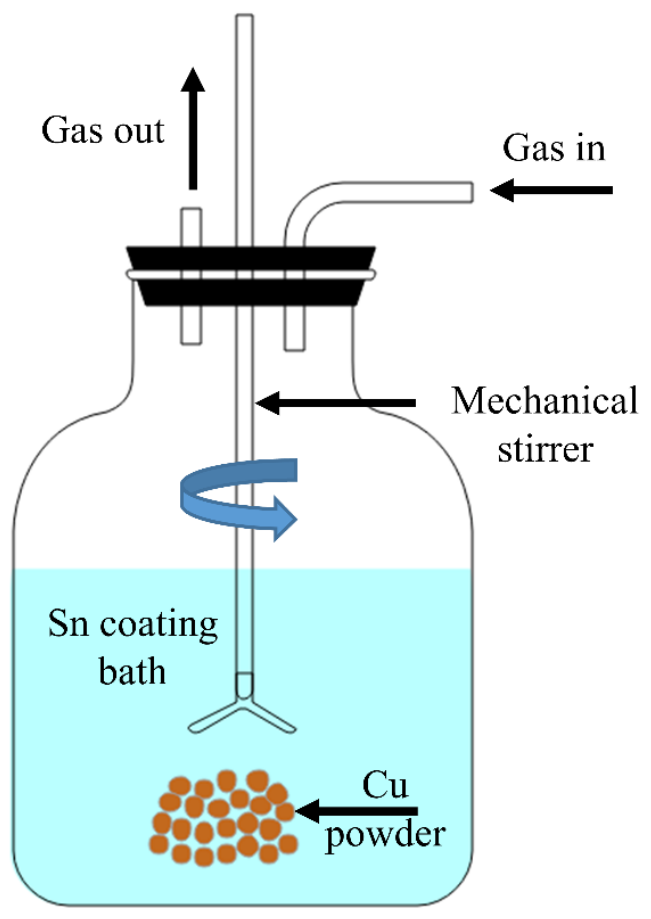

Figure 2: Schematic of the immersion tin coating process setup.

Figure 2 shows a schematic of the tin coating process setup that was used during the coating experiments. Metallic tin was coated on the surface of copper powder particles using the immersion plating technique. The entire tin coating process can be sub-divided into three steps: (1) Powder pretreatment, (2) Tin coating, and (3) Drying. The first step, i.e., powder pretreatment, was done to ensure that the surface of the virgin copper powder particles is free from oxides and surfacecontaminations. During the pretreatment step, the copper powder was first degreased in a magnetically stirred alkaline solution (BONDERITE ${ }^{\circledR}$ C-AK RST, Henkel Belgium NV) for $5 \mathrm{~min}$ at $80{ }^{\circ} \mathrm{C}$. Subsequently, the copper powder was treated in a $0.1 \mathrm{M} \mathrm{HCl}$ solution for $1 \mathrm{~min}$ at room temperature to remove the surface oxides. Note that after both acid and alkaline pretreatment steps, the copper powder was rinsed at least three times with demineralized water. Subsequently, the pretreated copper powder was transferred to a mechanically stirred immersion plating bath maintained at room temperature for 
the tin coating process. Table 1 summarizes two different experimental conditions that were used to produce tin-coated copper powders. The original recipe (i.e. the sub-optimal condition, the resulting tin-coated copper powder hereafter referred to as the R1 or high (910 ppm) sulfur-containing powder) was obtained from Mel'nikov et al. [40]. The original recipe was diluted to half of its original concentration (i.e. the optimal condition, the resulting tin-coated copper powder hereafter referred to as the R2 or low (20 ppm) sulfur-containing powder) to limit the amount of tin below $0.5 \mathrm{wt} \%$ in the alloyed parts processed from the tin-coated copper powder. This low tin content is necessary to retain the high electrical and thermal conductivity of copper. The coating experiment corresponding to the R1 powder was performed in the air atmosphere, whereas the coating experiment corresponding to the R2 powder was performed in an argon atmosphere to minimize the sulfur pickup during the tin coating process. The absence of oxygen in the latter case does not allow decomposition of thiourea, releasing sulfur ions at the copper surface. Hence, the low sulfur content in the R2 powder was realized, when the tin coating process was performed in an argon atmosphere. Note that the virgin copper powder contained only $8 \mathrm{ppm}$ of sulfur before applying the tin coating. All coating experiments were performed for a coating duration of 15 minutes on a copper powder batch size of $300 \mathrm{~g}$. Table 1 indicates the corresponding amounts of tin, sulfur, and oxygen in wt\%, resulting from the respective tin coating processes. The tin content was measured by the inductively coupled plasma optical emission spectrometry (ICP-OES) technique, while sulfur and oxygen contents were determined using the combustion techniques of Leco.

Table 1: Summary of the experimental conditions that were used during the tin coating experiments.

\begin{tabular}{|c|c|c|c|c|c|c|c|c|c|}
\hline \multicolumn{4}{|c|}{$\begin{array}{l}\text { Plating bath composition (recipe) } \\
\text { for } 1 \text { liter of demineralized water }\end{array}$} & \multirow{2}{*}{ Atmosphere } & \multirow{2}{*}{$\begin{array}{c}\mathrm{Sn} \\
\mathrm{wt} \%\end{array}$} & \multirow{2}{*}{$\begin{array}{c}\mathrm{S} \\
\mathrm{wt} \%\end{array}$} & \multirow{2}{*}{$\begin{array}{c}\mathrm{O} \\
\mathrm{wt} \%\end{array}$} & \multirow{2}{*}{ Category } & \multirow{2}{*}{$\begin{array}{l}\text { Coating } \\
\text { process } \\
\text { condition }\end{array}$} \\
\hline Powder & $\begin{array}{c}* \mathrm{SnCl}_{2} \\
(\mathrm{~g})\end{array}$ & $\begin{array}{l}* * \mathrm{TU} \\
(\mathrm{g})\end{array}$ & $\begin{array}{c}* * * \mathrm{TA} \\
(\mathrm{ml})\end{array}$ & & & & & & \\
\hline $\mathrm{R} 1$ & 5.5 & 50 & 35 & Air & 1.36 & 0.091 & 0.23 & $\begin{array}{l}\text { High } \\
\text { sulfur }\end{array}$ & $\begin{array}{c}\text { Sub- } \\
\text { optimal }\end{array}$ \\
\hline $\mathrm{R} 2$ & 2.75 & 25 & 17.5 & Argon & 0.28 & 0.002 & 0.045 & $\begin{array}{l}\text { Low } \\
\text { sulfur }\end{array}$ & Optimal \\
\hline \multicolumn{10}{|c|}{$\begin{array}{l}\text { Where, } \\
\text { * } \mathrm{SnCl}_{2} \text { - Tin(II) Chloride, } \\
\text { **TU - ThioUrea, } \\
\text { ***TA - Tartaric Acid }\end{array}$} \\
\hline
\end{tabular}

Both virgin (before coating) and tin-coated copper powders were characterized for the powder packing density, flowability, and optical absorption. The apparent and tapped (powder packing) density values were measured as per the ASTM B212 and ASTM B527, respectively. The powder flowability was measured using both the Hall flow (ASTM B213) and the dynamic angle of repose (dAoR) test. The optical absorption of powders was measured within the $400-1400 \mathrm{~nm}$ wavelength range at room temperature using a lambda 950 spectrophotometer of PerkinElmer. The thickness of the coated tin layer was measured after cutting an R2 powder particle with a focused ion Ga beam positioned in a scanning electron microscope (FIB-SEM, Dual-beam, Nova 600 Nanolab, FEI). The X-ray diffraction measurements were performed within the $10-80^{\circ} 2 \theta$ range using a Bruker D2 machine facilitated with a $\mathrm{Cu} \mathrm{Ka} \mathrm{X-ray} \mathrm{source.}$ 


\subsection{LPBF Process Optimization, Part Fabrication, and Characterization}

The LPBF process optimization was performed on both $\mathrm{R} 1$ and $\mathrm{R} 2$ powders using an in-house built LPBF machine at KU Leuven, Belgium. This machine is equipped with a continuous-wave, singlemode $1 \mathrm{~kW}$ fiber laser emitting laser light of $1080 \mathrm{~nm}$ wavelength [41]. The fiber laser has a beam diameter of $40 \mu \mathrm{m} 1 / \mathrm{e}^{2}$ value and a Gaussian intensity distribution profile. All samples were fabricated without laser beam defocusing in a flowing argon atmosphere on a non-preheated pure copper baseplate while maintaining the oxygen level in the build chamber below $50 \mathrm{ppm}$. 3D parts were designed and sliced using the Magics software provided by Materialise, Belgium. During the process optimization, cube-shaped parts with dimensions of $(10 \times 10 \times 7) \mathrm{mm}^{3}$ were fabricated by varying the laser power $(P)$ from 300 to $500 \mathrm{~W}$, the scan speed $(v)$ from 200 to $1200 \mathrm{~mm} / \mathrm{s}$, and the hatch spacing $(h)$ from 0.09 to $0.105 \mathrm{~mm}$, while the powder layer thickness $(t)$ was fixed at $0.03 \mathrm{~mm}$. A zig-zag (bi-directional) strategy was used to scan each layer, whereas a $90^{\circ}$ rotation strategy was employed to scan successive layers. The density of the fabricated parts was measured using the Archimedes method, and the relative part density values were reported considering $8.8577 \mathrm{~g} / \mathrm{cm}^{3}$ as the reference density value measured for the tin-coated copper powder using a Multipycnometer ${ }^{\mathrm{TM}}$ of Quantachrome Instruments. The optimized LPBF parameter setting ( $P$ of $500 \mathrm{~W}, v$ of $600 \mathrm{~mm} / \mathrm{s}, h$ of $0.105 \mathrm{~mm}$ ) that yielded $99.6 \%$ part density, when using the R2 powder, was chosen to produce electrical conductivity bars and dog-bone-shaped flat tensile bars. The electrical conductivity was measured at room temperature on six samples with dimensions of $(60 \times 5 \times 2) \mathrm{mm}^{3}$ using a four-point contact method on the Resistomat ${ }^{\circledR}$, model 2301V001, of Burster, Germany. The thermal conductivity was theoretically calculated based on the electrical conductivity measurements using the Wiedemann-Franz law, considering $\mathrm{L}=2.41 \times 10^{-8}$

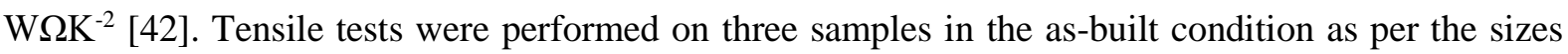
mentioned in ISO 6892 standard on an Instron 4467 machine by applying a cross-head speed of 0.4 $\mathrm{mm} / \mathrm{min}$. Microstructural analysis was performed on the cross-sectional surface of the mirror-polished samples. The samples were observed in the polished condition as well as after chemical etching. The chemical etching was performed by immersing the polished sample in a solution comprised of $2.5 \mathrm{ml}$ of $\mathrm{HCl}, 3.5 \mathrm{~g}$ of $\mathrm{FeCl}_{3}$, and $75 \mathrm{ml}$ of ethanol for a duration of $15 \mathrm{sec}$. Subsequently, the samples were washed with water and then with ethanol before they were dried under forced air. Microstructures of the samples were observed by light optical microscopy (3D Digital Microscope, Keyence, VHX-6000, and Axioskop $40 \mathrm{Pol} / 40 \mathrm{~A}$ Pol, Zeiss) and scanning electron microscopy (XL30 FEG, Philips). The energy-dispersive X-ray spectroscopy (EDS) analysis was performed using a Team ${ }^{\mathrm{TM}}$ EDS system coupled with scanning electron microscopes (XL30 FEG, Philips, and FIB-SEM, Dual-beam, Nova 600 Nanolab, FEI).

\section{Results}

\subsection{Powder Characterization}

\subsubsection{Powder Packing Density and Flowability}

Table 2 summarizes the powder packing (apparent and tapped) density and the flowability of R1 and R2 powders along with the virgin copper powder that is provided for reference. In general, R1 and R2 powders demonstrate better powder properties, such as apparent, tapped density, and flowability compared to the virgin copper powder. 
Table 2: Properties of R1 and R2 powders along with the virgin copper powder. Lower average angle of repose (AoR) value indicates better powder flowability.

\begin{tabular}{lccc}
\hline Property & Virgin Cu & R1 & R2 \\
\hline Apparent density (\%) & $47 \pm 2$ & $53 \pm 3$ & $50 \pm 0.3$ \\
Tapped density (\%) & $57 \pm 1$ & $59 \pm 1$ & $57 \pm 1$ \\
Hall flow time (s) & No flow & $13 \pm 1$ & $13 \pm 1$ \\
Average AoR $\left(^{\circ}\right)$ & $43 \pm 12$ & $29 \pm 3$ & $28 \pm 2$ \\
\hline
\end{tabular}

\subsubsection{Powder Optical Absorption}

Figure 3 shows the room temperature optical absorption (\%) of R1, R2, pre-alloyed (gas-

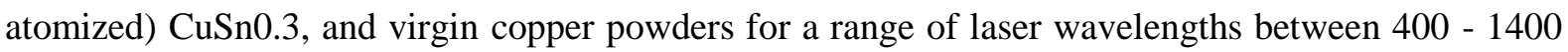
$\mathrm{nm}$. The fiber laser wavelength of $1080 \mathrm{~nm}$ is indicated using a vertical black dashed line. At the fiber laser wavelength, the lowest optical absorption of $19 \%$ is observed for the virgin copper powder. Prealloying of copper with a $0.3 \mathrm{wt} \%$ of tin results in slightly improved powder optical absorption (26\%). However, when a similar amount $(0.28 \mathrm{wt} \%)$ of tin is coated on the copper powder particles (R2), a drastic improvement in the powder optical absorption is realized, reaching a value of $51 \%$. Further increase of the tin coating content from 0.28 to $1.36 \mathrm{wt} \%$, i.e., for the R1 powder, did not significantly improve the powder optical absorption at the fiber laser wavelength compared to the R2 powder. This indicates that the powder optical absorption reaches rather a saturation value upon coating a tin content of $0.28 \mathrm{wt} \%$ on the surface of the copper particles. However, in general, a substantially higher powder optical absorption is observed for both R1 and R2 powders compared to the pre-alloyed $\mathrm{CuSn} 0.3$ and virgin copper powders.

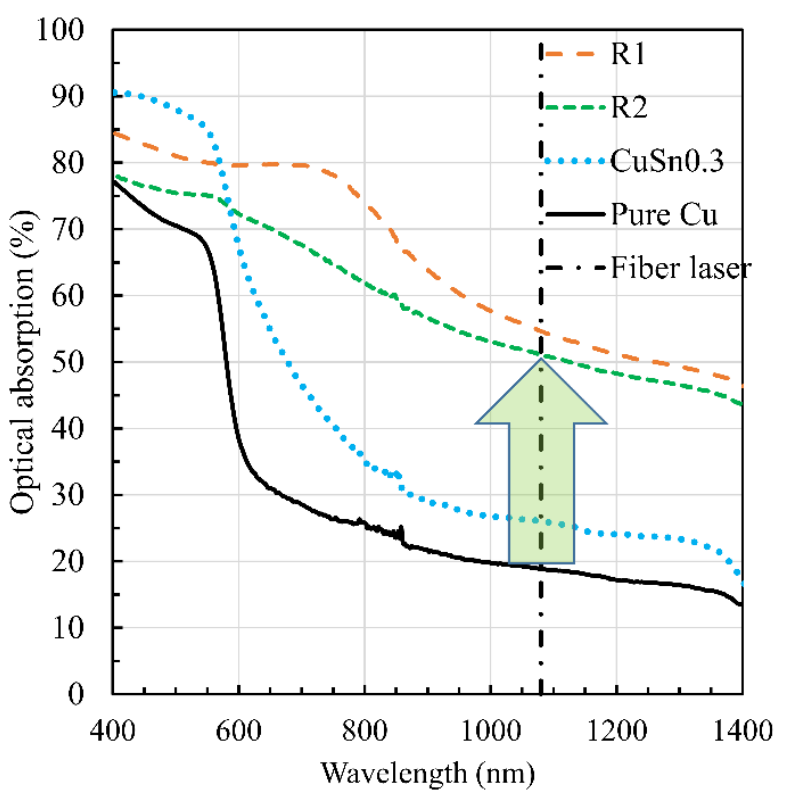

Figure 3: Optical absorption of R1 and R2 powders along with the pre-alloyed $\mathrm{CuSn} 0.3$ and (virgin) pure copper powders presented for a range of wavelengths from 400 to 1400 nm.

\subsubsection{Powder Surface Observation and EDS Mapping}

Figures 4(a, c, and f) show digital images of pure copper, R1, and R2 powders, respectively. As seen, pure copper powder is reddish in color, while after tin coating, the powder color is changed to 
greenish-gray for the R1 powder, and grey for the R2 powder. Figures 4(b, d, and g) show SEM images of the surface of copper powders before and after the tin coating process. The surface of pure copper powder is relatively smooth with some satellite particles attached. The surface of the R1 powder is rough, while it is less rough for the R2 powder. Both $\mathrm{R} 1$ and $\mathrm{R} 2$ powders show the presence of tin on the surface of copper powder particles, as validated by the corresponding EDS elemental maps of tin by purple and red color in Figures 4(e and $h$ ) and the XRD spectra in supplementary Figure 1. However, a local increase in the tin concentration is visible as bright spots on the surface of the R1 powder, as indicated in Figures 4(d and e).
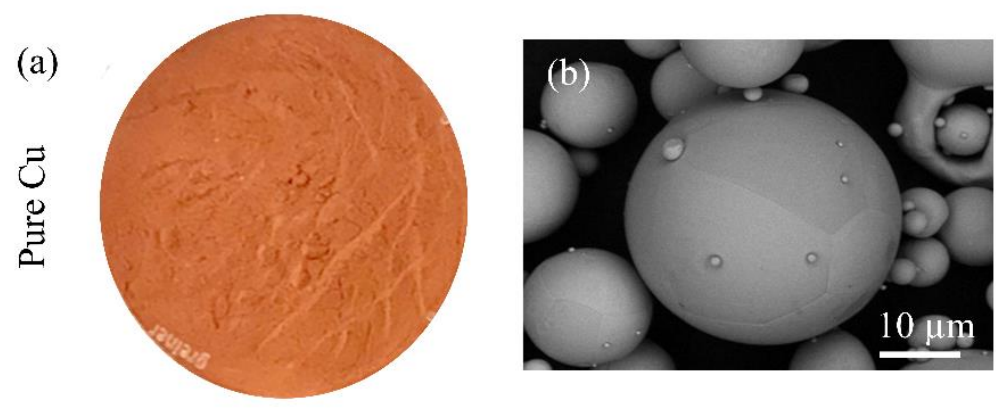

No image
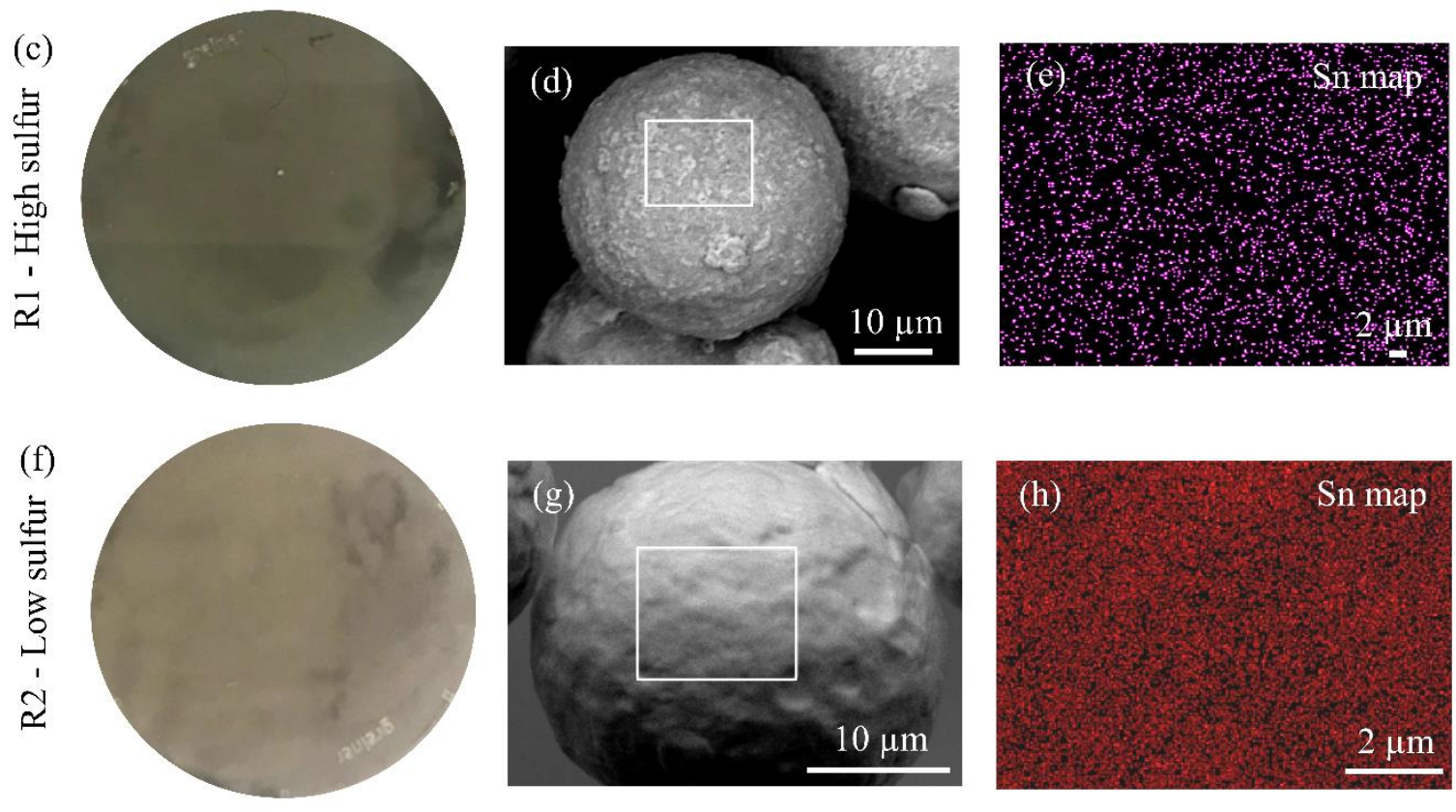

Figure 4: Digital images of (a) pure copper, (c) R1, (f) R2 powders. SEM images of the surface of (b) pure copper, (d) R1, (g) R2 powders. EDS maps for the elemental tin content are presented for (e) R1 and (h) R2 powders.

\subsection{LPBF Processing Behavior of High (R1) and Low (R2) Sulfur-containing Powders}

Figure 5 shows the evolution of the relative part density (\%) as a function of the applied volumetric laser energy density $\left(\mathrm{J} / \mathrm{mm}^{3}\right.$ ) for (a) high (R1) and (b) low (R2) sulfur-containing tin-coated copper powders. Generally, the relative part density increases with increase in the applied volumetric laser energy density, except for the low sulfur-containing powder-based parts (R2-LPBF) processed at a laser power of $500 \mathrm{~W}$. Moreover, the use of higher laser power or lower scan speed often improves the relative part density. Figure 5(a) shows that a maximum relative part density of only $94.3 \%$ can be 
obtained when a laser power of $500 \mathrm{~W}$ is employed. This means that laser power values $\leq 500 \mathrm{~W}$ do not allow the fabrication of dense copper parts from the R1 powder for the selected range of LPBF settings, PSD, and the non-preheated pure copper baseplate. However, Figure 5(b) demonstrates that a $99.6 \%$ dense copper part (encircled by a green color dashed circle) can be successfully processed by employing a volumetric laser energy density of $265 \mathrm{~J} / \mathrm{mm}^{3}$, which is generated by applying a laser power of $500 \mathrm{~W}$ and laser scan speed $(v)$ of $600 \mathrm{~mm} / \mathrm{s}$. Moreover, the use of the R2 powder generally produces copper parts with much higher part densities compared to the parts produced with the R1 powder at the same LPBF settings. This result indicates that there exists a significant LPBF processability difference between the R1 and R2 powders. Figure 5(b) further indicates that copper parts exceeding $98 \%$ relative density can only be fabricated using a laser power of $500 \mathrm{~W}$ within the volumetric laser energy density range of $190-400 \mathrm{~J} / \mathrm{mm}^{3}$. Application of lower or higher volumetric energy density values results in the decrease of the relative part density, when applying a laser power of $500 \mathrm{~W}$. On the other hand, the use of 300 or $400 \mathrm{~W}$ laser power displays a continuous increasing relative part density trend as a function of the volumetric laser energy density without reaching the peak density value within the selected range of LPBF settings.
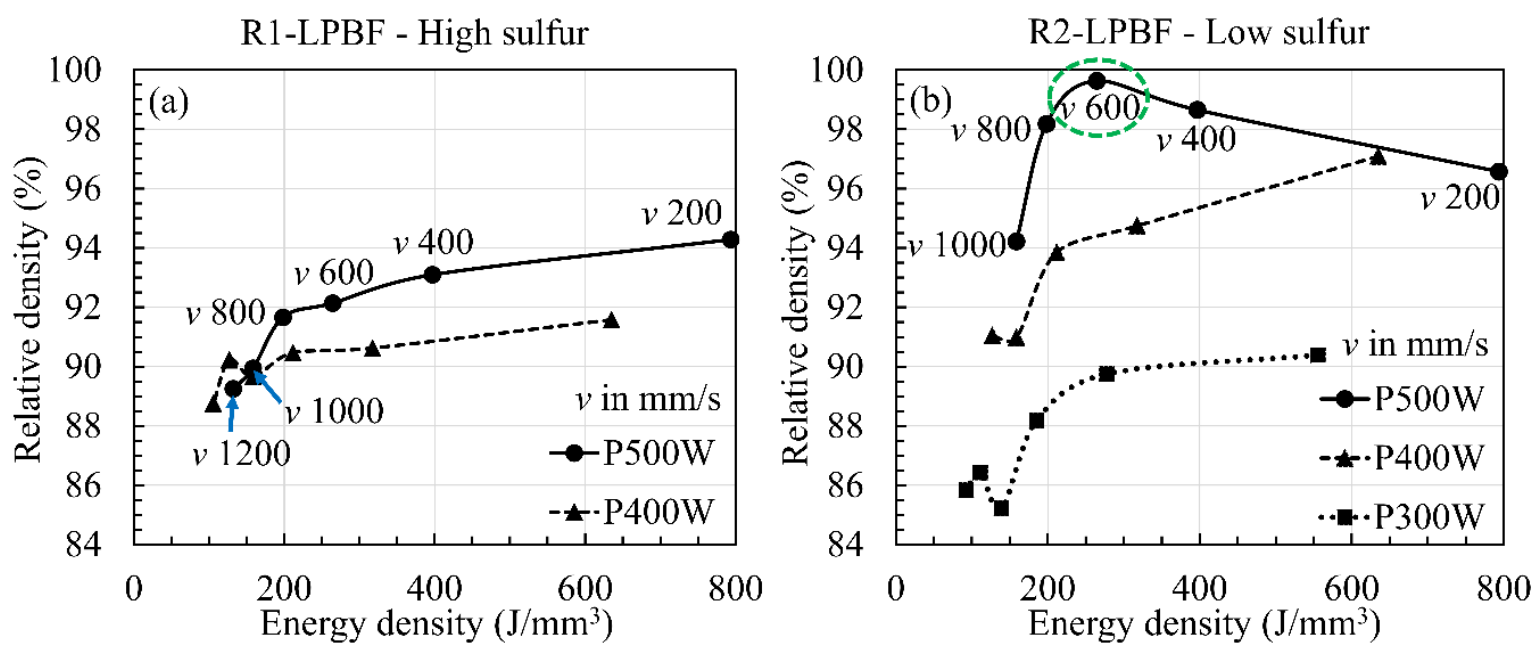

Figure 5: LPBF processing behavior of (a) high (R1) and (b) low (R2) sulfur-containing tin-coated copper powders are represented using graphs of relative part density (\%) as a function of energy density $\left(\mathrm{J} / \mathrm{mm}^{3}\right)$. The laser scan speed $(v)$ is denoted in $\mathrm{mm} / \mathrm{s}$ for the $500 \mathrm{~W}$ laser power $(P)$ data set.

\subsection{Part Characterization}

\subsubsection{Top Surface Observation}

Figures 6(a-f) show SEM images of the top surfaces of the parts produced using R1 and R2 powders. The top surfaces are displayed for the parts processed by using laser scan speeds $(v)$ of 200,600, and $1000 \mathrm{~mm} / \mathrm{s}$, when the laser power $(P)$ and hatch spacing $(h)$ were fixed at $500 \mathrm{~W}$ and $0.105 \mathrm{~mm}$, respectively. Generally, the top surfaces of the parts fabricated with the R2 powder show stable melt tracks along with a minor amount of surface porosities, while the high sulfur-containing powder-based (R1-LPBF) parts reveal unstable melt tracks with many surface porosities, marked by white arrows. The surface porosities of the R1-LPBF parts are mainly present at the borders of the adjacent laser scan tracks, as indicated in Figure 6(b) using white arrows situated next to the blue dashed lines. However, the porosity located at the laser scan track border is not observed for the R2-LPBF parts processed at laser scan speeds $(v)$ of 200 and $600 \mathrm{~mm} / \mathrm{s}$. The absence of porosity between neighboring laser tracks 
of the R2-LPBF parts is attributed to the sufficient overlap between the neighboring laser scan tracks. The melt pool shape and laser scanning direction (SD) are indicated in Figure 6(e) using yellow dashed curvatures and arrows, respectively. Finally, it can be visualized that the melt pools obtained for the R2-LPBF parts are wider in size compared to the melt pools of the R1-LPBF parts when the same LPBF scan settings are applied.
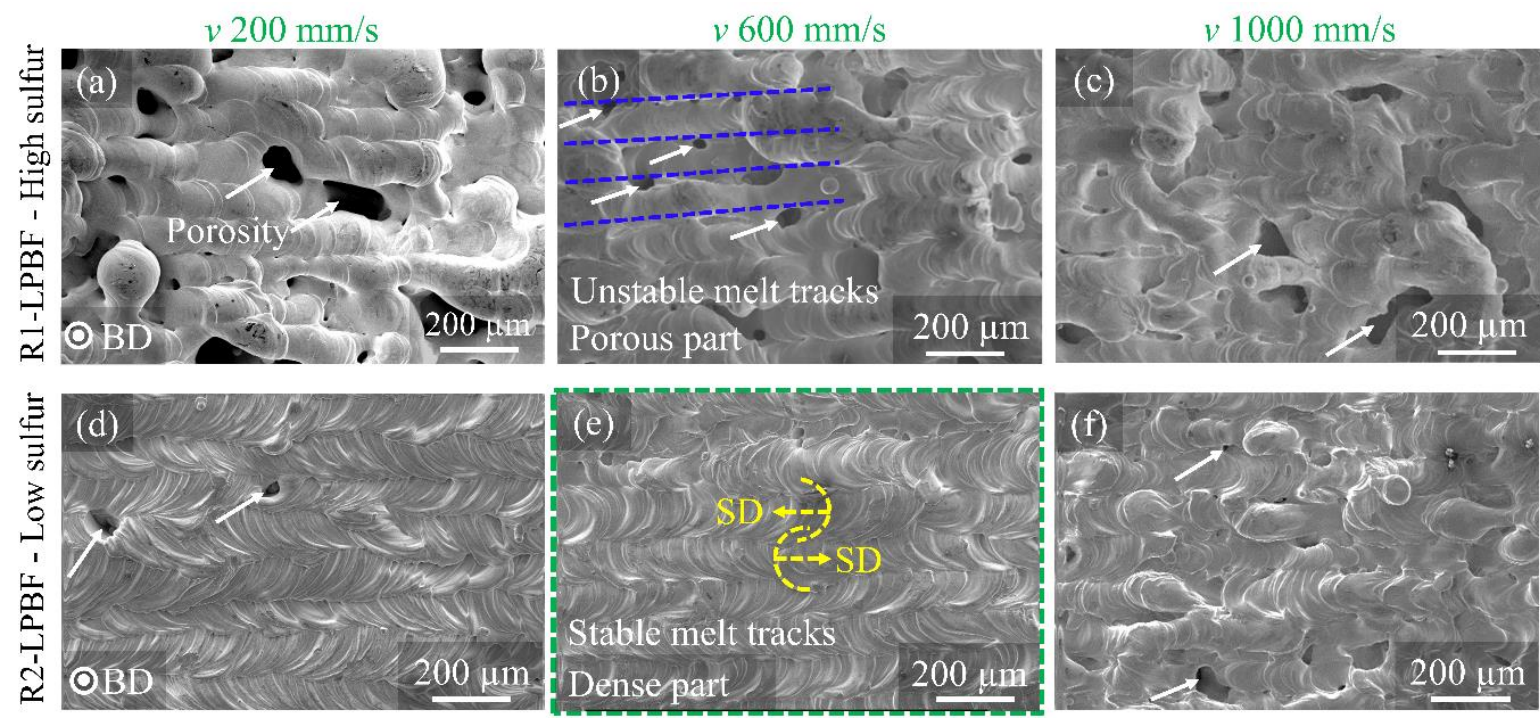

Figure 6: SEM images of the top surface of the R1-LPBF and R2-LPBF parts in the as-built condition. The parts are processed by using a fixed laser power $(P)$ of $500 \mathrm{~W}$, a hatch spacing $(h)$ of $0.105 \mathrm{~mm}$, and various laser scan speeds (v) of (a \& d) 200, (b \& e) 600, and (c \& f) $1000 \mathrm{~mm} / \mathrm{s}$.

\subsubsection{Cross-sectional Surface Observation}

Figures 7(a-f) show the cross-sectional surfaces of the parts produced using R1 and R2 powders in the as-polished condition. The cross-sectional surfaces are presented for the parts processed at different laser scan speeds $(v)$ of 200,600 , and $1000 \mathrm{~mm} / \mathrm{s}$ and with a fixed applied laser power $(P)$ and hatch spacing $(h)$ of $500 \mathrm{~W}$ and $0.105 \mathrm{~mm}$, respectively. The relative part density of each part is indicated on the top right corner of the respective Figures, and the porosity and cracks are marked using white- and red-colored arrows, respectively. In general, parts fabricated with the R1 powder exhibit a higher porosity content compared to the parts fabricated with the R2 powder, when evaluated for the same applied LPBF settings. The porosity content trend observed on the cross-sectional surface is in accordance with both the relative part density trend presented in Figure 5 and the top surface observations revealed in Figure 6. For the R1-LPBF parts, as the laser scan speed $(v)$ increases from 200 to $1000 \mathrm{~mm} / \mathrm{s}$, the porosity content in the part also increases, as seen in Figures 7(a-c). In contrast, for the R2-LPBF parts, the lowest porosity content is observed for the part that is processed at a laser scan speed of $600 \mathrm{~mm} / \mathrm{s}$, which is outlined using a green dashed rectangle in Figure 7(e). Lowering or increasing the laser scan speed value, lower or higher than $600 \mathrm{~mm} / \mathrm{s}$, respectively, allowing the laser scan speed to vary between 200 and $1000 \mathrm{~mm} / \mathrm{s}$, resulted in an increase in the porosity content, as shown in Figures 7(d) or 7(f), respectively. Thus, the highest relative density of $99.6 \%$ is observed for the part which is fabricated by employing a laser power of $500 \mathrm{~W}$, a laser scan speed of $600 \mathrm{~mm} / \mathrm{s}$, a hatch spacing of $0.105 \mathrm{~mm}$, and a powder layer thickness of $0.03 \mathrm{~mm}$. Finally, it is important to note that the R1-LPBF parts exhibit very long ( $>1 \mathrm{~mm}$ ) cracks that are oriented parallel to the building direction (BD), as indicated in Figure 7(a). Moreover, the density of these cracks is highest for the part processed 
at low laser scan speed $(v)$ of $200 \mathrm{~mm} / \mathrm{s}$, while the crack density seemingly decreases at the higher laser scan speeds, such as 600 and $1000 \mathrm{~mm} / \mathrm{s}$ (also refer to Supplementary Figure 2). The observed crack density reduction for the parts processed at higher laser scan speeds could be a delusion caused by the presence of a large amount of porosity. On the contrary, the R2-LPBF parts do not show any evidence of such cracks, regardless of the employed LPBF settings.
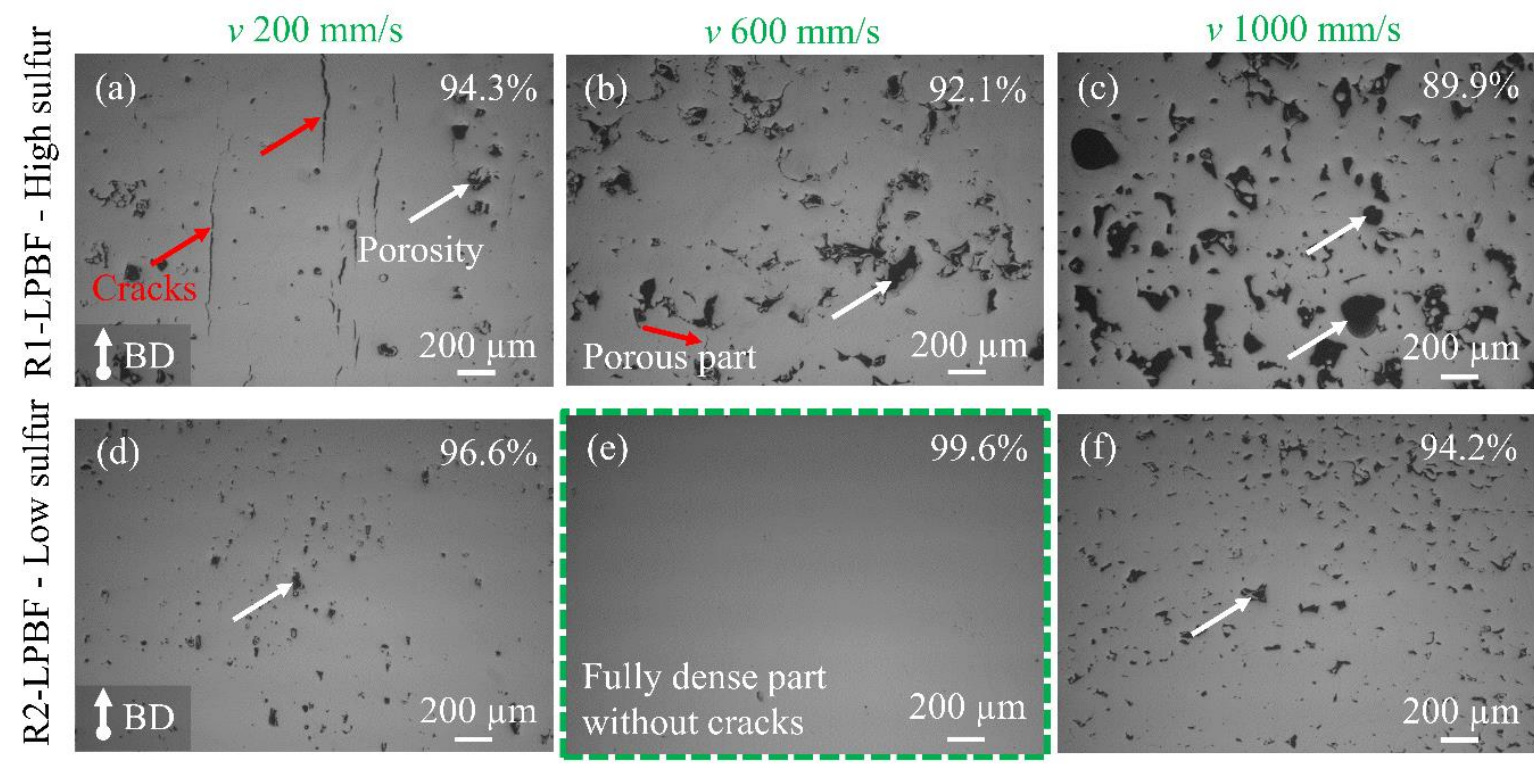

Figure 7: Cross-sectional surfaces of the R1-LPBF and R2-LPBF parts in the as-polished condition. The parts are processed by using a fixed laser power $(P)$ of $500 \mathrm{~W}$, a hatch spacing $(h)$ of $0.105 \mathrm{~mm}$, and various laser scan speeds ( $v$ ) of (a \& d) 200, (b \& e) 600, and (c \& f) $1000 \mathrm{~mm} / \mathrm{s}$.

Figures $8(\mathrm{a}-\mathrm{f})$ show the cross-sectional surfaces of the upper few layers of the parts produced using R1 and R2 powders in the etched condition. The melt pools are outlined using yellow dashed curves, and the porosity and cracks are denoted by white- and red-colored arrows, respectively. Overall, stable melt pools, indicated by consistent depths, are observed for the R2-LPBF parts, while unstable melt pools, represented by inconsistent depths, are visible for the R1-LPBF parts. Generally, the melt pool depth is decreased when the applied laser scan speed is increased. Consequently, porous parts with 'lack of fusion' defects are obtained when the parts are scanned at a high laser scan speed of $1000 \mathrm{~mm} / \mathrm{s}$, regardless of the starting powder composition. Cross-sectional surface images of the R1-LPBF parts displayed in Figures 7(a-c) showed that the cracks were oriented parallel to the building direction (BD). Those cracks are actually located at the center of the melt pool, as indicated by red arrows in Figures 8(a-c). On the contrary, the R2-LPBF parts do not show any evidence of such cracking in Figures 8(df). This means that the significant reduction in the sulfur content avoided the crack formation during the LPBF process (also refer to Supplementary Figure 2). Furthermore, for the R2-LPBF parts with laser scan speeds of 200 and $1000 \mathrm{~mm} / \mathrm{s}$, their porosity can be identified as the keyhole induced porosity and the lack of fusion porosity, respectively. Note that the keyhole induced porosity is formed by trapping bubbles of metal vapors or shielding gas at the bottom of the deep keyhole-mode melt pools, as denoted in Figure 8(d). On the other hand, the 'lack of fusion porosity' is formed due to the incomplete fusion of the powder particles and the poor overlap between melt pools of the subsequent layers, as indicated in Figure 8(f). 

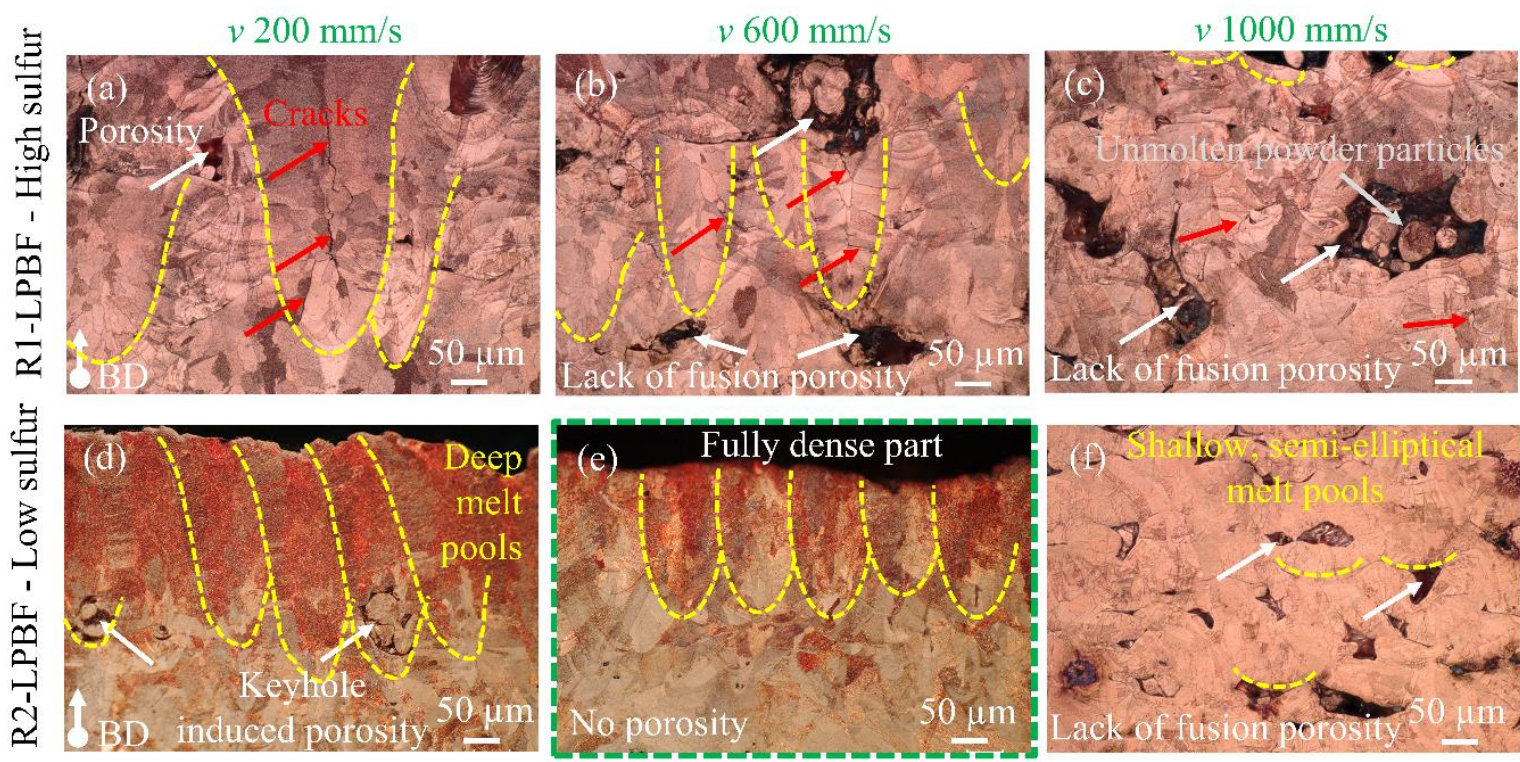

Figure 8: Cross-sectional surfaces of the R1-LPBF and R2-LPBF parts in the etched condition. The parts were fabricated using a fixed laser power $(P)$ of $500 \mathrm{~W}$, a hatch spacing $(h)$ of $0.105 \mathrm{~mm}$, and various laser scan speeds $(v)$ of $(a \&$ d) 200 , (b \& e) 600 , and $(c \&$ f) $1000 \mathrm{~mm} / \mathrm{s}$.

\subsubsection{Characterization of Cracks Observed in the High Sulfur-containing Powder-based (R1-LPBF) Parts}

\subsubsection{SEM Analysis}

Figures $9(\mathrm{a} \& \mathrm{~b})$ and $(\mathrm{c} \& \mathrm{~d})$ show a detailed view of the top and cross-sectional surfaces of the R1LPBF part processed by applying a laser power of $500 \mathrm{~W}$, a laser scan speed of $200 \mathrm{~mm} / \mathrm{s}$, and a hatch spacing of $0.105 \mathrm{~mm}$, respectively. The melt pool borders are marked using yellow dashed curves, and the cracks are denoted using red arrows. Both surfaces show the presence of cracks within the melt pools. Generally, the crack width is larger at the melt pool center, while it decreases near the melt pool border. It is important to note that the cracks are not only located at the melt pool center but also at the melt pool borders. Furthermore, the cracks present near melt pool borders are preferentially oriented perpendicular to the melt pool border, and because of their finer width, they are poorly visible at lower magnifications. 

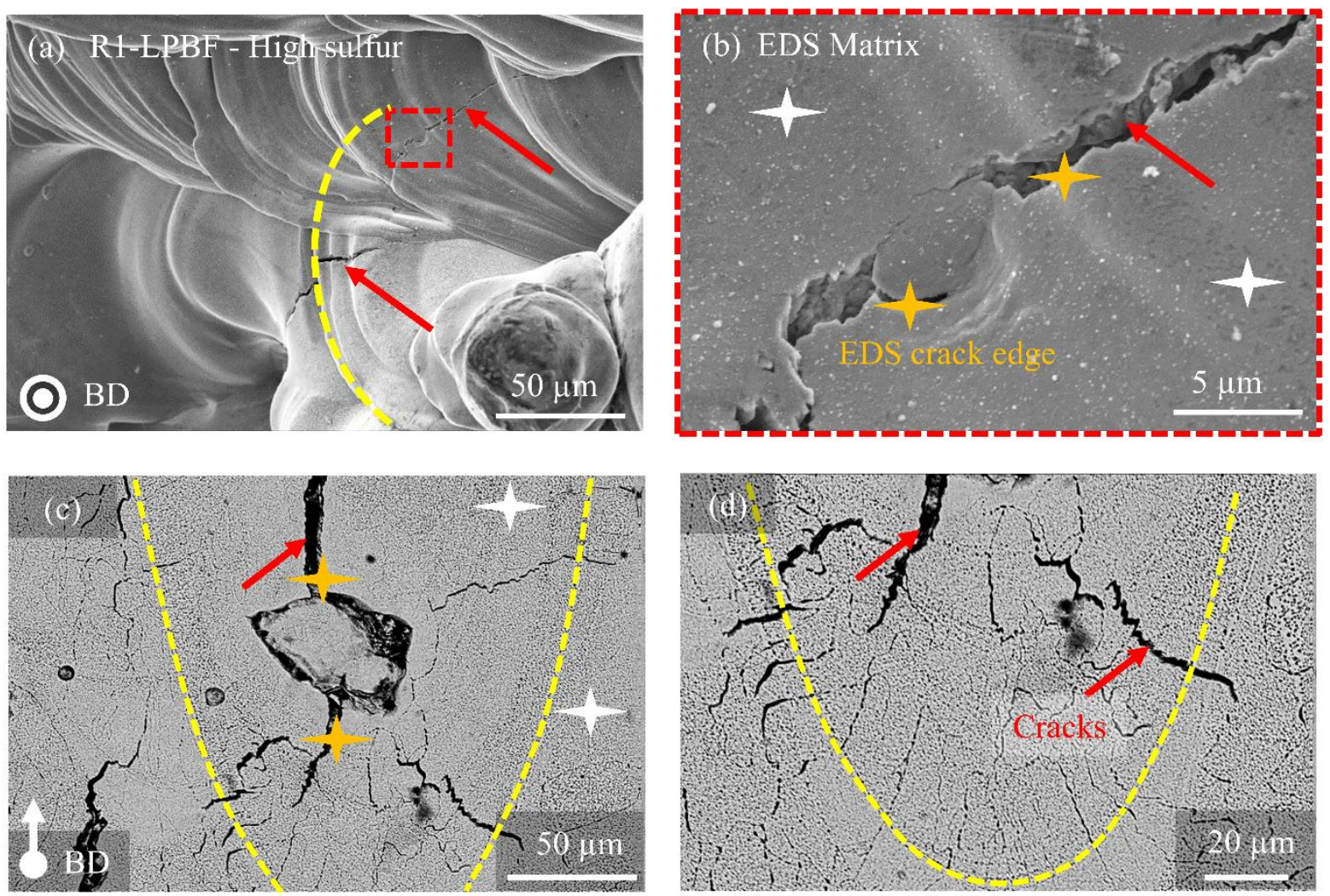

Figure 9: A closer view of the top (a \& b) and cross-sectional (c \& d) surfaces of the R1-LPBF part processed by using a laser power of $500 \mathrm{~W}$, a laser scan speed of $200 \mathrm{~mm} / \mathrm{s}$, and a hatch spacing of $0.105 \mathrm{~mm}$.

\subsubsection{EDS Analysis}

EDS spot analysis was performed at the crack edge as well as in the matrix. Representative locations of such EDS spot measurements are shown in Figures 9(b \& c) using orange- and whitecolored stars for the crack edge and matrix, respectively. In total, a minimum of fourteen EDS spot measurements were performed at each of the two locations (i.e. at the crack edge and in the matrix), and the average values of those measurements are reported in Figure 10. Moreover, an EDS mapping was performed to display the location of different phases and their chemical constituents with respect to the crack edge and the matrix. A representative EDS map, which is displayed after overlapping of the individual ( $\mathrm{Sn}, \mathrm{S}, \mathrm{O}$, and $\mathrm{Cu}$ ) elemental maps, along with the corresponding backscattered electron (BSE) image is displayed in the inset of Figure 10(b).

Figure 10(a) shows a cumulative fractional amount of alloying and impurity elements (i.e. Sn $+\mathrm{S}+\mathrm{O}$ ) over the base metal (i.e. $\mathrm{Cu}$ ) present at the crack edge and in the matrix. As seen, a higher concentration of alloying and impurity elements is observed at the crack edge compared to the matrix. This means that the segregation of $\mathrm{Sn}, \mathrm{S}$, and $\mathrm{O}$ has occurred at the crack edge during solidification. Furthermore, Figure 10(b) is plotted to identify relative concentrations of each of the alloying and impurity elements at the crack edge and matrix. The relative concentration of tin and oxygen is higher in the matrix compared to the crack edge, when only the alloying and impurity elements are considered (i.e. excluding the base metal $\mathrm{Cu}$ ). However, the relative amount of sulfur at the crack edge is higher than in the matrix, when only the alloying and impurity elements are considered. This indicates that the phase present at the crack edge, comprised of $\mathrm{Sn}, \mathrm{S}$, and/or $\mathrm{O}$, is enriched in sulfur compared to the phase that exists in the matrix. 
Within the EDS map, three different colors, namely red, blue, and yellow, corresponding to different phase compositions, could be identified. The red color represents a uniform distribution of the pure copper phase. The blue color denotes a phase that is comprised of mainly copper and tin; thus, it is possibly a uniformly distributed CuSn solid solution phase. Finally, the yellow color, located mainly at the crack edge, signifies a phase that is relatively rich in sulfur and oxygen compared to the red- and blue-colored phases. Along with sulfur and oxygen, the yellow-colored phase also contains copper and tin; thus, it could be a mixture of phases containing metal-oxides and metal-sulfides.

Accordingly, the EDS spot analysis and the EDS mapping measurements render two insights. First, alloying ( $\mathrm{Sn}$ ) and impurity elements ( $\mathrm{S}$ and $\mathrm{O}$ ) are segregated at the crack edge. Second, the phase present at the crack edge is enriched in sulfur compared to the phase that is present in the matrix.

(a)

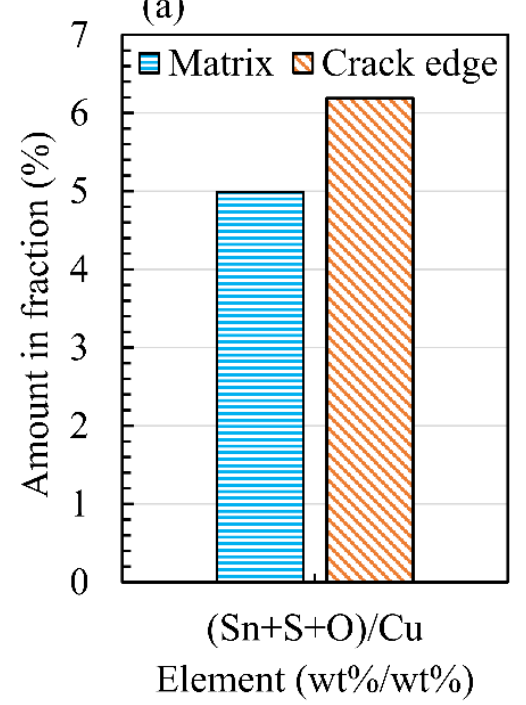

(b)

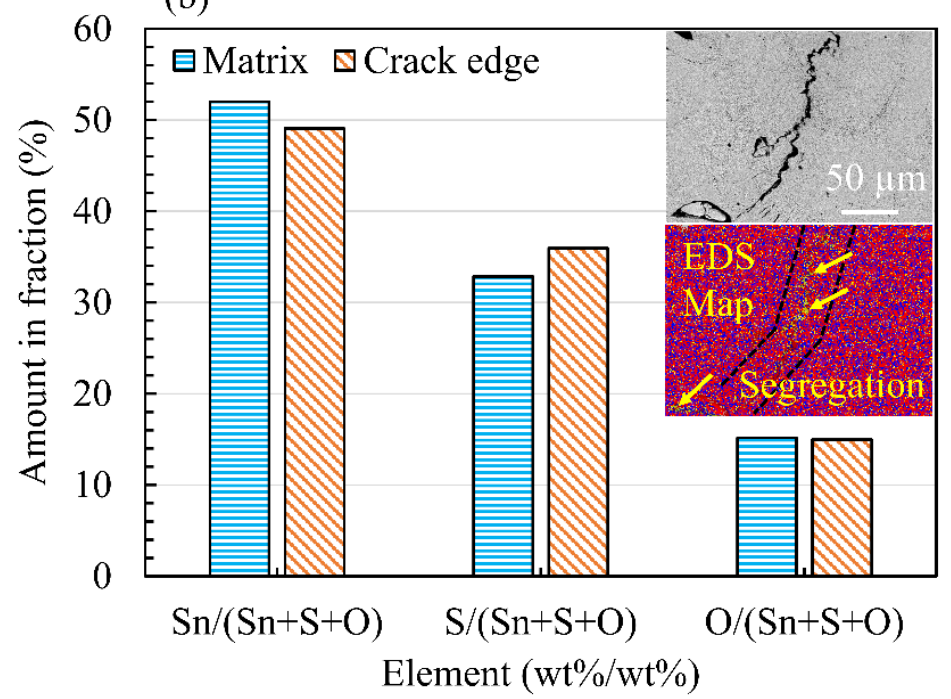

Figure 10: (a) \% Fractional amount of alloying ( $\mathrm{Sn}$ ) and impurity elements ( $\mathrm{S}$ and $\mathrm{O}$ ) over the matrix metal $(\mathrm{Cu})$ measured at the crack edge and in the matrix. (b) \% Fractional amount of each of the alloying or impurity elements measured at the crack edge and in the matrix. The inset shows a BSE image and the corresponding EDS map at the cross-sectional surface of an R1-LPBF part. As seen, a yellow-colored phase, indicated by yellow-colored arrows, is segregated at the crack edge. The yellow-colored phase is relatively rich in sulfur and oxygen compared to the red- (pure copper) and blue-colored (CuSn solid solution) phases.

\subsubsection{Mechanical, Electrical, and Thermal Properties of the Fully Dense and Chemically Homogeneous R2-LPBF Parts}

Since the R2 powder exhibited a high room temperature optical absorption (51\%) and low sulfur $(0.002 \mathrm{wt} \%)$ and oxygen $(0.045 \mathrm{wt} \%)$ content, fully dense $\mathrm{CuSn} 0.3$ parts without any segregation of its chemical constituents can be fabricated via LPBF, as shown in Figure 11 by elemental EDS maps. Subsequently, the mechanical, electrical, and thermal properties of the fully dense and chemically homogeneous R2-LPBF parts were determined in the as-built condition and are reported in Table 3 with a label CuSn0.3 (R2-LPBF). The corresponding properties of a CuCr0.3 alloy [5] and pure copper [21] are provided for comparison. As seen, the $\mathrm{CuSn} 0.3$ (R2-LPBF) parts generally exhibit better mechanical properties compared to both $\mathrm{CuCr} 0.3$ and pure copper parts in the as-built condition. Moreover, the electrical and thermal conductivity values of the CuSn0.3 (R2-LPBF) parts are higher than the $\mathrm{CuCr} 0.3$ alloy parts; however, they are lower compared to the pure copper parts in the as-built condition. This result indicates that the better combination of strength and conductivity, in the as-built condition, 
required for heat transfer and electrical components could be obtained by LPBF processing of the tincoated copper powders.
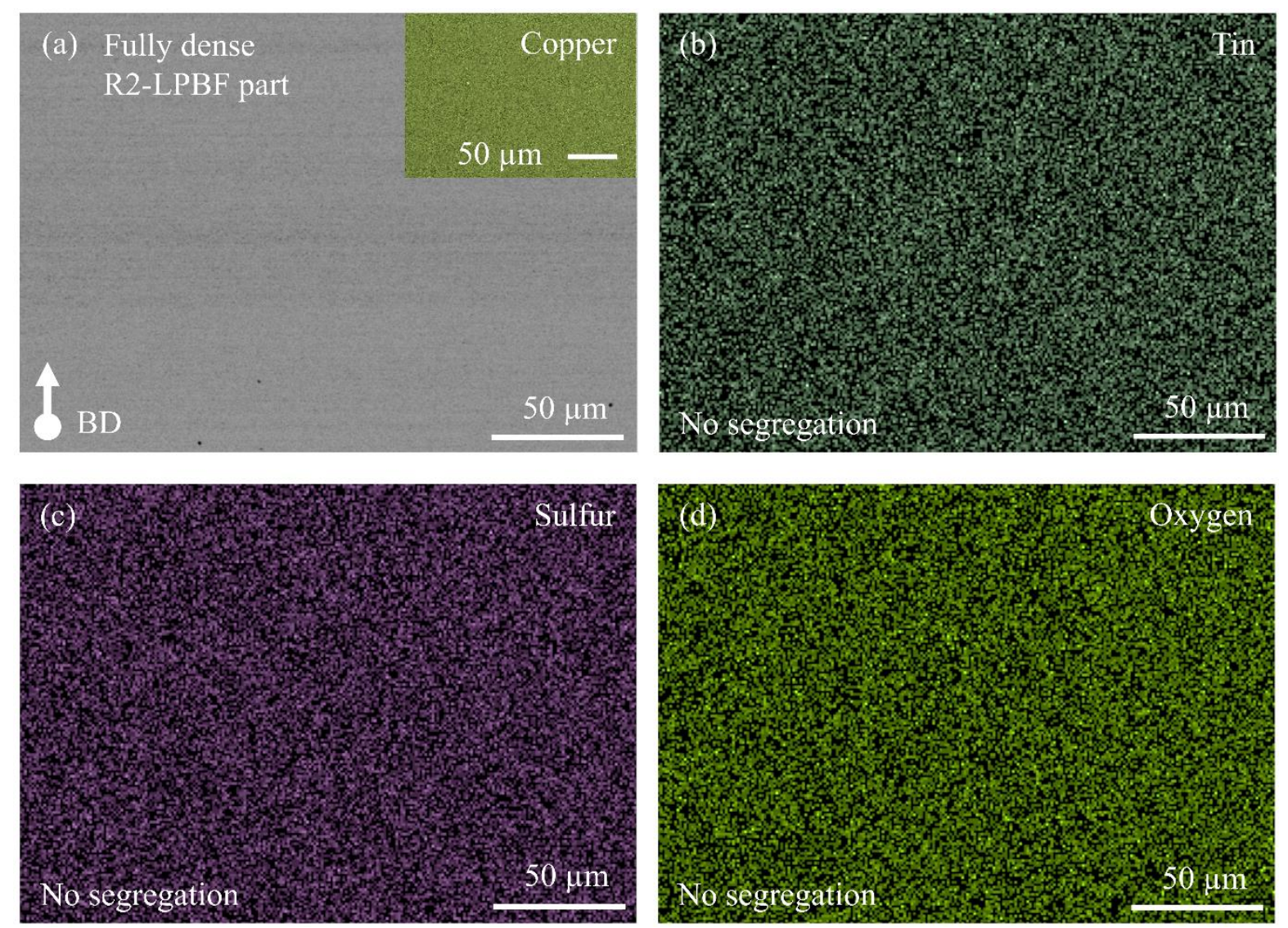

Figure 11: (a) SEM image of the cross-sectional surface of a fully dense R2-LPBF part. The distribution of elements on the cross-sectional surface is shown by EDS mapping for (a) copper (in the inset), (b) tin, (c) sulfur, and (d) oxygen. As seen, the R2-LPBF part exhibits a homogeneous distribution of its chemical constituents, unlike the case of the R1-LPBF part. Since the amount of sulfur and oxygen was negligible in the $\mathrm{R} 2$ powder, it can be assumed that the R2-LPBF part mainly consists of copper- and tin-containing phases.

Table 3: Mechanical, electrical, and thermal properties of the LPBF as-built parts fabricated with the R2 powder and labeled as CuSn0.3 (R2-LPBF). The properties of a CuCr0.3 alloy- [5] and pure copper-based parts [21] in the as-built condition are provided for comparison.

\begin{tabular}{lccc}
\hline \multicolumn{1}{c}{ Property } & $\begin{array}{c}\text { CuSn0.3 } \\
\text { (R2-LPBF) }\end{array}$ & $\begin{array}{c}\text { CuCr0.3 } \\
{[5]}\end{array}$ & $\begin{array}{c}\text { Cu } \\
{[21]}\end{array}$ \\
\hline Tensile strength (MPa) & $256 \pm 14$ & $221 \pm 5$ & - \\
Yield strength (MPa) & $203 \pm 4$ & $117 \pm 1$ & - \\
Elongation at break (\%) & $21 \pm 2$ & $32 \pm 1$ & - \\
Hardness (HV0.3) & $90 \pm 3$ & $77 \pm 3$ & $65 \pm 2$ \\
Electrical conductivity (IACS \%) & $80 \pm 1$ & $69 \pm 2$ & $88 \pm 2$ \\
Thermal conductivity (W/(m.K)) & $334 \pm 4$ & $291 \pm 8$ & $369 \pm 8$ \\
\hline
\end{tabular}

Where,

IACS: International annealed copper standard $\left(100 \%=58 \times 10^{6} \mathrm{~S} / \mathrm{m}\right)$ 


\section{Discussion}

\subsection{Improvement in the Powder Properties}

\subsubsection{Powder Flowability}

Table 2 showed that both R1 and R2 powders exhibit better flowability compared to the corresponding pure copper powder before coating. The cohesive forces (Van der Waals) that determine the powder flowability are generally dependent on the surface energy of the material and the true contact area between the neighboring powder particles [43]. Moreover, the cohesive forces are normally effective over very small length scales in the range of one to several angstroms. Assuming that there is a negligible change in the true contact area between the neighboring powder particles after application of the tin coating, the surface energy of the material that is present at the outer surface of the powder particles should play a crucial role in determining the powder flowability. Accordingly, the improvement in the powder flowability after applying the tin coating could be attributed to two factors: Firstly, to the low surface energy of tin $\left(574 \mathrm{~mJ} / \mathrm{m}^{2}\right.$ [44]) compared to the high surface energy of copper $\left(1650 \mathrm{~mJ} / \mathrm{m}^{2}\right.$ [45]). Secondly, to the tin coating layer exhibiting a thickness of several nanometers, which eliminated the prior high-energy copper-copper cohesive forces that used to exist between the neighboring copper powder particles before application of the tin coating.

\subsubsection{Powder Optical Absorption}

Figure 3 showed that, at the fiber laser wavelength, both R1 and R2 powders demonstrate substantial improvement in the powder optical absorption compared to the pre-alloyed CuSn0.3 and pure copper powders. To explain the powder optical absorption improvement, the optical absorption values and optical penetration depths of electromagnetic radiation in bulk solid tin and copper substrates were theoretically calculated using the Fresnel law and the Beer-Lambert law, respectively. The optical constants, such as the extinction coefficient $(k)$ and refractive index $(n)$, required for the calculations were obtained from Golovashkin et al. [46] and CRC handbook of chemistry and physics [47] for tin and copper, respectively. After the calculations, a graph of the optical absorption (A) and optical penetration depth $(\delta \mathrm{p})$ as a function of the wavelength of the electromagnetic radiation can be plotted, as shown in Figure 12(a). At the fiber laser wavelength, pure tin exhibits much higher optical absorption $(\sim 21 \%)$ compared to pure copper $(\sim 3 \%)$. Note that the values presented in this graph correspond to a flat solid surface at the normal incidence angle, and thus these optical absorption values are much lower compared to the respective metals in their powder form. Metals in their powder form generally exhibit much higher optical absorption values, since the powder particles allow the penetration of incoming laser light between the powder particles resulting in multiple internal reflections and elevation of the optical absorption. Furthermore, Figures 12(b-d) show an R2 powder particle (b) before and (c \& d) after FIB cutting. The FIB cutting plane is marked using a white dashed line in Figure 12(b), and the border of the dark-colored tin coating layer is denoted using yellow dashed curves in Figure 12(d). Note that the presence of tin $(9.7 \mathrm{wt} \%)$ is confirmed by performing the EDS spot analysis within the darkcolored coating layer, as shown for a representative location in Figure 12(d), indicated by a blackcolored star. Figures 12(b-d) show that a tin coating corresponding to the addition of $0.28 \mathrm{wt} \%$ tin has a coating thickness of $62 \pm 14 \mathrm{~nm}$. Since the coating thickness is higher than the theoretical optical penetration depth $(\delta \mathrm{p}: 11 \mathrm{~nm})$ of $1080 \mathrm{~nm}$ laser light, the $0.28 \mathrm{wt} \%$ tin addition is considered to be sufficient for increasing the powder optical absorption substantially. Hence, the coating recipe corresponding to the $\mathrm{R} 2$ powder is considered as the optimum processing methodology. The substantial improvement observed in the powder optical absorption of the tin-coated copper powders could be attributed to the high optical absorption of tin and the low optical penetration depth of the laser light within tin $(\delta \mathrm{p}: 11 \mathrm{~nm})$ and copper $(\delta \mathrm{p}: 12 \mathrm{~nm})$, at the fiber laser wavelength. Although a similar amount of tin $(0.3 \mathrm{wt} \%)$ was present in the pre-alloyed $\mathrm{CuSn} 0.3$ powder, a significantly lower powder optical 
absorption was observed for the pre-alloyed powder compared to the R2 powder. This could be attributed to the uniform or random distribution of tin within the pre-alloyed powder particles in contrast to the preferential presence of tin on the surface of the R2 powder particles. Finally, the slightly higher optical absorption of the $\mathrm{R} 1$ powder compared to the $\mathrm{R} 2$ powder could be attributed to the presence of a higher amount of tin $(1.3 \mathrm{wt} \%)$ in the former powder, which makes that almost all the copper powder particles are coated with sufficient coating thickness. Moreover, the presence of a higher oxygen and sulfur content in the R1 powder could also enhance the optical absorption of the powder by trapping the incoming optical radiation within a metal-oxide or metal-sulfide layer that exists at the powder surface, as demonstrated earlier in $[31,48,49]$.
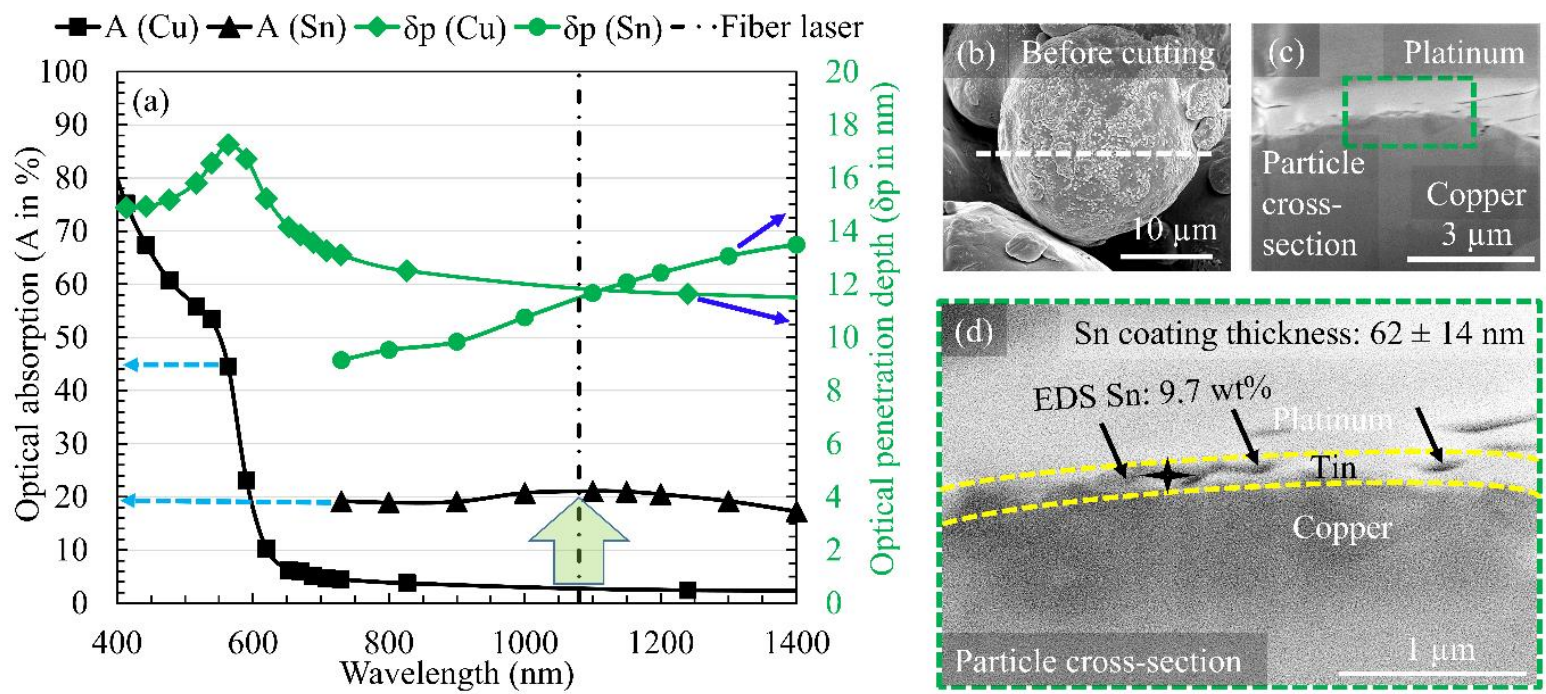

Figure 12: (a) Theoretically calculated optical absorption values and optical penetration depths of electromagnetic radiation for pure tin and copper substrates. (b) SEM image of an R2 powder particle before FIB cutting. (c) SEM image of the R2 powder particle after FIB cutting. (d) A magnified view of the cross-sectional surface of the powder particle indicating the presence of a very thin $(62 \pm 14$ $\mathrm{nm}$ ) layer of tin, as confirmed by the EDS spot analysis. Note that the tin coating layer was very thin; therefore, some part of the coating layer is not clearly visible due to the smearing of the platinum layer over the tin layer caused by the severe FIB cutting operation.

\subsection{LPBF Processing Behavior}

\subsubsection{LPBF of High (R1) and Low (R2) Sulfur-containing Tin-coated copper Powders}

Figures 5 - 8 showed that the use of R1 powder did not allow the fabrication of crack-free and dense copper parts within the selected LPBF settings. On the contrary, the R2 powder yielded a $99.6 \%$ dense and crack-free copper part when a volumetric laser energy density of $265 \mathrm{~J} / \mathrm{mm}^{3}$ was applied using a laser power of $500 \mathrm{~W}$. Figure 6(b) showed that the porosity observed for the R1-LPBF part is mainly located at the melt track borders, and it is caused by the poor overlap between the neighboring melt tracks. In contrast, a sufficient overlap between the neighboring melt pools, without obvious porosity at the melt tracks borders, was observed for the corresponding R2-LPBF part. Accordingly, melt pool widths of both powder-based parts processed with the same LPBF setting $(P$ of $500 \mathrm{~W}, v$ of $600 \mathrm{~mm} / \mathrm{s}$, and $h$ of $0.105 \mathrm{~mm}$ ) are measured. The part fabricated using the R1 powder demonstrate a smaller melt pool width of $110 \pm 20 \mu \mathrm{m}$, whereas a larger melt pool width of $154 \pm 18 \mu \mathrm{m}$ is observed for the part produced from the R2 powder. Since the melt pool widths of the R1-LPBF part are comparable to the employed hatch spacing of $105 \mu \mathrm{m}$, the lack of overlap between neighboring melt tracks and the 
concomitant porosity formation is expected. The difference in the melt pool widths observed for the R1-LPBF and R2-LPBF parts can be explained by the change in the Marangoni effect, as shown in Figure 13 [50]. Generally, a melt pool formed during the LPBF process with a Gaussian beam exhibits the highest temperature at the melt pool centerline, and the temperature gradually decreases towards the melt pool borders, i.e., towards the melt pool fusion line. This temperature profile across the melt pool generates a negative surface tension gradient for pure metals and alloys without surface-active elements, as shown schematically in Figure 13(d) [51]. Therefore, the molten metal flows from the center of the melt pool to the melt pool borders, as illustrated in Figure 13(e). (i.e., the molten metal flows from the low to high surface tension gradient as per the Marangoni effect) [52]. Accordingly, wider melt pools with sufficient overlap between the neighboring melt tracks were observed for the parts processed with the R2 powder, as revealed in Figure 13(f). However, the addition of a surface-active element, such as sulfur in an amount of $930 \mathrm{ppm}$ in the copper melt, substantially reduces the surface tension of the pure copper melt by $0.43 \mathrm{~N} / \mathrm{m}$ at $1120^{\circ} \mathrm{C}$ [53]. Moreover, the sulfur addition could shift the surface tension gradient from a negative to a positive value, as displayed schematically in Figure 13(a). This change in surface tension gradient causes inversion of the melt flow within the melt pool, as indicated in Figure 13(b). Consequently, a melt pool with narrower width is realized [50,54]. Since the width of the generated melt pool is similar to the employed hatch spacing, a poor melt pool overlap with concomitant porosity was observed for the R1-LPBF part, as revealed in Figure 13(c). The slight changes in the tin ( 0.28 or $1.36 \mathrm{wt} \%)$ and oxygen $(0.045$ or $0.23 \mathrm{wt} \%)$ content within copper alloys do not seem to significantly affect the melt pool widths, since prior studies on LPBF of copper powders had already demonstrated the formation of wider melt pools with sufficient overlap when the hatch spacing in the range of $90-105 \mu \mathrm{m}$ was used [21,31,38]. Moreover, the top surface of the parts produced using a tincoated copper powder containing the same tin content of $0.28 \mathrm{wt} \%$ as the R 2 powder, but a higher sulfur content of $700 \mathrm{ppm}$ revealed the presence of porosity between the neighboring melt tracks (refer to the supplementary Figure 2). Hence, the porosity formation could be attributed to the presence of high sulfur, which causes a lack of overlap between the neighboring melt tracks due to the inversion of the Marangoni melt flow within melt pools.
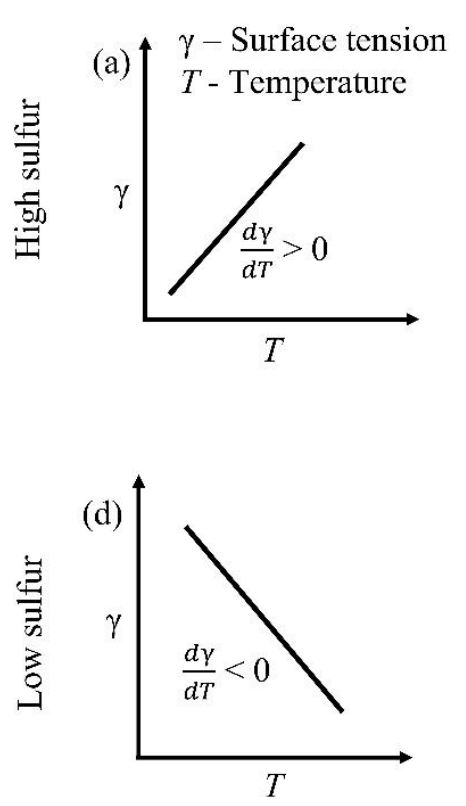

(b)
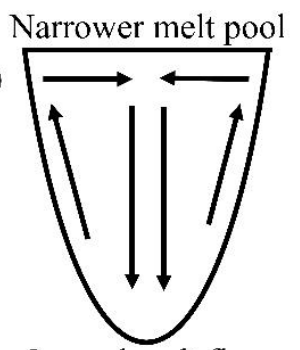

Inward melt flow Inverse Marangoni effect

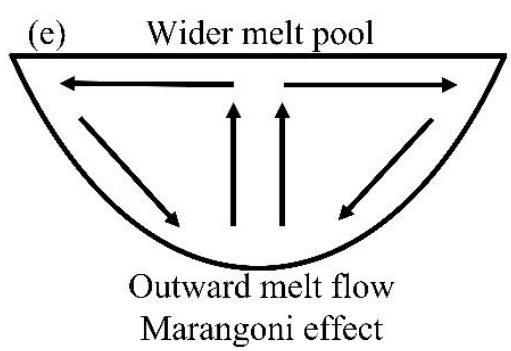

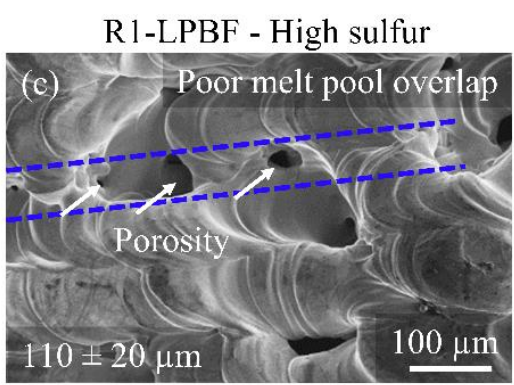

R2-LPBF - Low sulfur

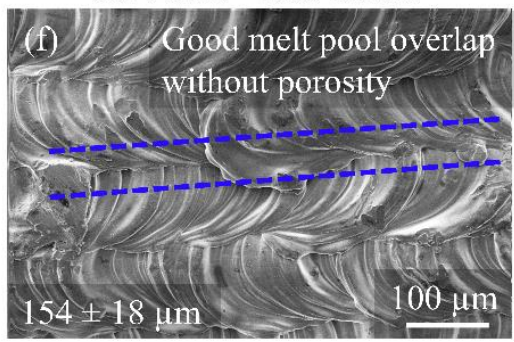

Figure 13: (a) \& (d) Schematic representation of a positive and negative surface tension gradient, respectively. (b) \& (e) Schematic representation of the molten metal flow within a melt pool for the 
case of a positive and negative surface tension gradient, respectively. (c) Narrower melt pools with surface porosity of the R1-LPBF part generated by the inverse Marangoni effect. (f) Wider melt pools of the R2-LPBF part produced by the Marangoni effect. The schematic figures (a, b, d, \& e) are reprinted from [50].

\subsubsection{Influence of the Laser Power and Laser Scan Speed on the LPBF Densification Behavior of Highly Conductive CuSn Alloy Powders}

Both R1 and R2 powders showed that the part density increases with an increase in the applied laser power or decrease of the laser scan speed except for the R2-LPBF parts processed using a laser power of $500 \mathrm{~W}$ in combination with a scan speed of $\leq 400 \mathrm{~mm} / \mathrm{s}$. Moreover, a laser power of 300 or $400 \mathrm{~W}$ did not allow the fabrication of fully dense CuSn alloy parts. The observed densification behavior and the simultaneous evolution of the part density trends can be explained by the dynamic nature of the laser absorption that takes place during the actual LPBF process and by the high thermal conductivity (334 $\pm 4 \mathrm{~W} /(\mathrm{m} \cdot \mathrm{K}))$ of the CuSn0.3 alloy. Trapp et al. [55] and Ye et al. [56] have demonstrated that during a typical LPBF process the real-time laser absorption is not only controlled by the optical absorptivity of the starting material but also by the geometry of the melt pool that is generated upon application of various LPBF settings. Since highly conductive copper alloys $(\geq 300 \mathrm{~W} /(\mathrm{m} \cdot \mathrm{K})$ ) exhibit low laser absorption in the solid and liquid state, a higher contribution to the total (real-time) laser absorption is desired from the melt pool geometry driven factor in order to achieve an enhancement in the part densification behavior. As such, a deep melt pool exhibiting a keyhole feature allows multiple internal reflections and subsequent absorption of the incoming laser light, whereas a shallow melt pool with a semi-elliptical geometry does not exhibit the keyhole feature, and therefore it reflects a major part of the irradiating laser light from the outer surface of the melt pool. Consequently, high-energydensity LPBF settings (high laser power and/or low laser scan speed) that result in the formation of a deep melt pool geometry with the keyhole feature favor the part densification, provided that the keyhole is fully filled by the liquid metal and that the gaseous bubbles are not trapped during solidification of the molten metal. On the other hand, low-energy-density LPBF settings (low laser power and/or high laser scan speed), which lead to the formation of a shallow and semi-elliptical shaped melt pool (commonly known as the conduction-controlled melt pool), or cause insufficient powder melting disfavor the part densification and result in the formation of 'lack of fusion' porosity between successively deposited powder layers. Accordingly, fully dense parts made of highly conductive copper alloys (thermal conductivity of $\geq 300 \mathrm{~W} /(\mathrm{m} \cdot \mathrm{K})$ in the as-built condition) can only be fabricated by applying a laser energy density that is high enough to create a keyhole mode melt pool, but not too high to induce the keyhole driven porosity. Since the laser power and laser scan speed have a significant influence on the laser energy density, a change in the applied laser power and/or scan speed will have a substantial influence on the melt pool geometry, as validated by Cunningham et al. [57]. Hence, the increasing trend of relative part density with increase of the applied laser power and/or decrease of laser scan speed could be attributed to the enhancement of the real-time optical absorption caused by the formation of a deep melt pool with the keyhole feature, while the decline in the relative density curve of the $500 \mathrm{~W}$ processed R2-LPBF parts at laser scan speeds below $400 \mathrm{~mm} / \mathrm{s}$ could be attributed to the application of a very high laser energy density which results in the formation keyhole induced porosity, as validated in Figure 7(d) and Figure 8(d). Finally, the successful fabrication of a fully dense R2-LPBF part at the laser power of $500 \mathrm{~W}$ demonstrated that this laser power is sufficient to cause complete fusion of the R2 powder particles. On the other hand, a laser power of 300 or $400 \mathrm{~W}$ did not allow to process full density parts indicating that these laser power levels are not sufficient to cause complete fusion of the R2 powder particles for the selected range of LPBF settings, PSD, and the non-preheated pure copper baseplate. 


\subsection{Crack Formation in the High Sulfur-containing Powder-based (R1-LPBF) Parts}

Figures 7 - 9 showed that the R1-LPBF parts contain many cracks, whereas they were not observed within the parts fabricated with the R2 powder. The microstructural observation of those cracks revealed the cracks are oriented parallel to the building direction (BD) at the melt pool center, while perpendicular to the melt pool border at the fusion line. This means that the cracks were formed at the terminal stage of solidification, and they could exist in the intercellular region. The EDS analysis results in Figure 10 demonstrated that the crack edge is richer in the alloying $(\mathrm{Sn})$ and impurity $(\mathrm{S}$ and $\mathrm{O}$ ) elements compared to the matrix composition. Notably, the phase present at the crack edge is much richer in sulfur content. All the above-mentioned features are typical of a solidification cracking phenomenon, also known as hot cracking, and therefore these cracks can be labeled as the solidification cracks.

To identify the possible phases that could exist at the segregated area, i.e., at the crack edge, the amount of sulfur, oxygen, and tin present in the R1 powder along with all possible phases and their properties are outlined in Table 4. Generally, an element exhibiting a lower equilibrium solid solubility in the matrix tends to segregate at the melt pool front and can thus be found in the final solidifying liquid. Table 4 shows that the amount of sulfur, oxygen, and tin present in the R1 powder is higher than the equilibrium solid solubility of these elements in the copper matrix at room temperature. Therefore, during the solidification, their segregation at the center of the melt pool as well as in the intercellular region is plausible. Furthermore, Table 4 demonstrates that, in general, tin-oxides and tin-sulfides are more stable compared to copper-oxides and copper-sulfides, respectively. However, among the segregated elements at the crack edge, the relative amounts of sulfur and oxygen in at.\% (measured at locations that are representatively denoted in Figure 9 and deduced from the EDS measurements reported in Figure 10) are much higher compared to the tin. This means that the amount of tin that is present in the segregated area is not sufficient to convert all sulfur and oxygen into their respective sulfide and oxide forms. However, a very high amount of copper is available for such reactions. Hence, it could be stated that the segregated region (i.e. crack edge ) perhaps contains a mixture of tin-sulfides, copper-sulfides, tin-oxides, and copper-oxides. A solidification crack during the terminal stage of solidification generally occurs when a thin liquid film, exhibiting a lower liquidus temperature than the matrix, is ruptured by the tensile stresses generated due to the thermal and solidification shrinkage. The three sulfide phases, namely $\mathrm{SnS}_{2}, \mathrm{SnS}$, and/or $\mathrm{CuS}$, exhibit much lower liquidus temperatures compared to the matrix copper-tin alloy $\left(\sim 1080{ }^{\circ} \mathrm{C}\right)$. Therefore, perhaps, they are present in the segregated region and are responsible for the cracking of the R1-LPBF parts. It is important to note that both tin and oxygen, either in their elemental form or oxide forms, do not cause cracking issues within copper alloys. Accordingly, successful fabrication of crack-free and fully dense parts with varying amounts of tin and oxygen has been realized via LPBF $[35,36,38]$. On the other hand, a sulfur content of $\sim 500 \mathrm{ppm}$ is known to cause hot cracking during the laser welding of copper and copper alloys [1]. Moreover, the top surface of the parts fabricated using a tin-coated copper powder containing the same amount of tin as that of R2 powder (i.e. $0.28 \mathrm{wt} \%$ ), but a higher sulfur content of $700 \mathrm{ppm}$ revealed the presence of surface cracks along with the porosity between the neighboring melt tracks, as shown in Supplementary Figure 2. Consequently, the solidification cracking observed in the R1-LPBF parts could be attributed to the sulfur and sulfur-containing phases, which were inherited during the suboptimal tin coating process. 
Table 4: The amount of sulfur, oxygen, and tin present in the R1 powder along with all possible phases and their properties.

\begin{tabular}{cccccc}
\hline Phase & $\begin{array}{c}\text { Amount } \\
\text { in R1 } \\
\text { powder } \\
(\mathbf{w t \%})\end{array}$ & $\begin{array}{c}\text { Solid } \\
\text { solubility } \\
\text { in Cu @ RT } \\
(\mathbf{w t} \%)[4]\end{array}$ & $\begin{array}{c}\text { Melting point } \\
\left({ }^{\circ} \mathbf{C}\right)\end{array}$ & $\begin{array}{c}\mathbf{\Delta G} \\
(\mathbf{k J} / \mathbf{m})\end{array}$ & $\begin{array}{c}\text { EDS chemical } \\
\text { composition [crack } \\
\text { edge }- \text { matrix] } \\
(\text { at.\%) }\end{array}$ \\
\hline $\mathrm{S}$ & 0.091 & $<0.0025$ & 115 & {$[47,59]$} & 0.95 \\
$\mathrm{O}$ & 0.23 & 0.0002 & -219 & - & 0.52 \\
$\mathrm{Sn}$ & 1.36 & 1.2 & 232 & - & 0.17 \\
$\mathrm{Cr}$ & - & 0.03 & 1907 & - & - \\
$\mathrm{SnS}$ & - & - & 600 & -153.6 & - \\
$\mathrm{SnS}$ & - & - & 882 & -98.3 & - \\
$\mathrm{Cu} 2$ & - & - & 1130 & -86.2 & - \\
$\mathrm{CuS}$ & - & - & 500 & -53.6 & - \\
$\mathrm{SnO}$ & - & - & 1630 & -519.7 & - \\
$\mathrm{SnO}_{2}$ & - & - & 1080 & -256.9 & - \\
$\mathrm{Cu}_{2} \mathrm{O}$ & - & - & 1232 & -146 & - \\
$\mathrm{CuO}^{2}$ & - & - & 1326 & -129.7 & - \\
\hline $\mathrm{Wh}$ & - & - & & & \\
\hline
\end{tabular}

Where,

RT: Room temperature

$\Delta \mathrm{G}$ : Gibbs free energy

\section{Conclusions}

A novel approach of using optically absorptive metal-coated copper powders for the production of fully dense, highly conductive, and strong copper parts via LPBF is described. To demonstrate the viability of this approach, a very thin layer $(62 \pm 14 \mathrm{~nm})$ composed of metallic tin was applied on the surface of the copper powder particles using an immersion plating technique. The application of a 0.28 $\mathrm{wt} \%$ tin coating layer not only increased the room temperature optical absorption of the copper powder from 19 to $51 \%$ at the fiber laser wavelength of $1080 \mathrm{~nm}$ but also enhanced the powder flowability compared to pure copper powder before application of the coating. Consequently, crack-free and fully dense copper parts were successfully fabricated using a low $(20 \mathrm{ppm})$ sulfur-containing tin-coated copper powder (R2). In the as-built condition, the parts demonstrated a very good combination of electrical $(80 \pm 1 \mathrm{IACS} \%)$, thermal $(334 \pm 4 \mathrm{~W} /(\mathrm{m} \cdot \mathrm{K}))$, and mechanical (tensile strength of $256 \pm 14$ $\mathrm{MPa}$, yield strength of $203 \pm 4 \mathrm{MPa}$, and ductility of $21 \pm 2 \%$ ) properties.

Apart from the successful validation of the proposed idea, this research highlighted the negative influence of sulfur, incorporated in the tin coating during sub-optimal coating conditions, on the LPBF processing behavior of highly conductive CuSn alloys. Although the high (910 ppm) sulfur-containing tin-coated copper powder (R1) exhibited a high room temperature optical absorption of $55 \%$ at the fiber laser wavelength, crack-free and fully dense parts cannot be fabricated within the selected LPBF settings. The top surface and microstructural analysis of the high sulfur-containing R1-LPBF parts revealed the presence of an excessive amount of porosity and cracks. Since the porosity was preferentially located between the melt track borders and the melt pools were much narrower compared to the corresponding melt pools of the low sulfur-containing R2-LPBF parts, the porosity formation has been attributed to the poor overlap between the neighboring melt track caused by the inversion of the Marangoni flows within the molten metal. The cracks were oriented parallel to the building direction at the melt pool center, while at the melt pool border, they were perpendicular to the border. Moreover, 
the edges of the cracks were rich in sulfur, oxygen, and tin compared to the matrix. Hence, the cracks were identified as solidification cracks. The formation of the solidification cracks has been attributed to the rupture of thin films composed of $\mathrm{SnS}_{2}, \mathrm{SnS}$, and/or $\mathrm{CuS}$ phases exhibiting lower liquidus temperatures than the matrix under the influence of thermal- and solidification-driven tensile stresses during the terminal stage of solidification. However, the solidification cracking issue was successfully avoided by using a low sulfur-containing ( $20 \mathrm{ppm}$ ) tin-coated copper powder (R2). Accordingly, the use of sulfur-free powder is recommended for the fabrication of fully dense and crack-free copper parts via the LPBF process.

The proposed coating methodology can be applicable to a variety of metal-metal combinations and allows to coat coarser powders that can be processed by other laser-based AM techniques, such as Directed Energy Deposition (DED). Accordingly, this research paves a new path for the fabrication of complex-shaped thermal management and electrical components with a high thermal and electrical efficiency using metal-coated copper powders in the commercially available LPBF machines geared with fiber lasers.

\section{Acknowledgments}

This project was jointly funded by the Flanders Innovation \& Entrepreneurship Agency (Agentschap Innoveren en Ondernemen (VLAIO)) and Aurubis Belgium SA/NV in the framework of an $\mathrm{O} \& \mathrm{O}$ project '3D-Cu: 3D printing of highly conductive copper powders' (contract number HBC.2017.0479). The authors are thankful to Prof. Jan Van Humbeeck, Prof. Jean-Pierre Kruth, Prof. Sasan Dadbakhsh, Miss. Guichuan Li, Mr. Pushkar Prakash Dhekne, and Dr. Aljaz Ivekovic for their inputs on the metal coating process and the LPBF processing of copper alloy powders. The authors are grateful to Miss. Adrita Dass for performing a couple of tin coating experiments during her internship at KU Leuven, Belgium. The authors acknowledge that Ir. Yannis Kinds and Ir. Louca Goossens upgraded the LPBF machine by installing a $1 \mathrm{~kW}$ fiber laser.

\section{Author Contributions}

Conceptualization: S.D.J. and K.V.; Planning experimental design and first set of coating experiments: S.D.J and D.F.; Coating process optimization: D.F., M.D., and S.D.J.; LPBF optimization: S.D.J.; Powder and part characterization: D.F., S.D.J., K.R., D.W., and M.D., Interpretation of results: S.D.J., D.F., K.V., B.V.H., K.R., and D.W.; Wiring - original draft: S.D.J.; Writing - review and editing: K.V., B.V.H., S.D.J., D.F., and D.W., Funding acquisition: D.W., K.V., and B.V.H.

\section{Declaration of Interest Statement}

The authors declare that they have no known competing financial interests or personal relationships that could have appeared to influence the work reported in this paper.

\section{Data Availability}

The raw/processed data required to reproduce these findings can be made available upon request. 


\section{References}

[1] J.R. Davis, Associates, ASM Specialty Handbook® - Copper and Copper Alloys, ASM International, 2001. https://www.asminternational.org/documents/10192/1849770/ACFAA67.pdf.

[2] L. Constantin, Z. Wu, N. Li, L. Fan, J.-F. Silvain, Y.F. Lu, Laser 3D printing of Complex Copper Structures, Addit. Manuf. (2020) 101268. doi:10.1016/j.addma.2020.101268.

[3] N. Simpson, D.J. North, S.M. Collins, P.H. Mellor, Additive Manufacturing of Shaped Profile Windings for Minimal AC Loss in Electrical Machines, IEEE Trans. Ind. Appl. 56 (2020) 2510-2519. doi:10.1109/TIA.2020.2975763.

[4] R.N. Caron, Copper: Alloying, in: Encycl. Mater. Sci. Technol., Elsevier, 2001: pp. 16521660. doi:10.1016/B0-08-043152-6/00289-8.

[5] S.D. Jadhav, S. Dadbakhsh, R. Chen, R. Shabadi, J. Kruth, J. Van Humbeeck, K. Vanmeensel, Modification of Electrical and Mechanical Properties of Selective Laser-Melted CuCr0.3 Alloy Using Carbon Nanoparticles, Adv. Eng. Mater. 22 (2020) 1900946 (1-14). doi:10.1002/adem.201900946.

[6] D. Jafari, W.W. Wits, The utilization of selective laser melting technology on heat transfer devices for thermal energy conversion applications: A review, Renew. Sustain. Energy Rev. 91 (2018) 420-442. doi:10.1016/j.rser.2018.03.109.

[7] T. DebRoy, H.L. Wei, J.S. Zuback, T. Mukherjee, J.W. Elmer, J.O. Milewski, A.M. Beese, A. Wilson-Heid, A. De, W. Zhang, Additive manufacturing of metallic components - Process, structure and properties, Prog. Mater. Sci. 92 (2018) 112-224. doi:10.1016/j.pmatsci.2017.10.001.

[8] F. Lorenz, J. Rudolph, R. Wemer, Design of 3D Printed High Performance Windings for Switched Reluctance Machines, in: 2018 XIII Int. Conf. Electr. Mach., IEEE, 2018: pp. 24512457. doi:10.1109/ICELMACH.2018.8506845.

[9] T.Q. Tran, A. Chinnappan, J.K.Y. Lee, N.H. Loc, L.T. Tran, G. Wang, V.V. Kumar, W.A.D.M. Jayathilaka, D. Ji, M. Doddamani, S. Ramakrishna, 3D Printing of Highly Pure Copper, Metals (Basel). 9 (2019) 756. doi:10.3390/met9070756.

[10] P.A. Lykov, E.V. Safonov, A.M. Akhmedianov, Selective Laser Melting of Copper, Mater. Sci. Forum. 843 (2016) 284-288. doi:10.4028/www.scientific.net/MSF.843.284.

[11] F. Trevisan, C. Flaviana, M. Diego, F. Paolo, Selective laser melting of chemical pure copper powders, in: Euro PM2017, 2017: pp. 1-6. doi:10.1097/00000433-198206000-00020.

[12] C. Silbernagel, L. Gargalis, I. Ashcroft, R. Hague, M. Galea, P. Dickens, Electrical resistivity of pure copper processed by medium-powered laser powder bed fusion additive manufacturing for use in electromagnetic applications, Addit. Manuf. 29 (2019) 100831. doi:10.1016/j.addma.2019.100831.

[13] L.B. Benedetti, C.H. Ahrens, Study on selective laser melting of copper, in: $9^{\circ}$ Congr. Bras. Eng. Fabr., ABCM, Joinville, Santa Catarina, Brasil, 2017: pp. 1-10.

[14] R. Hönl, World premiere at Formnext: green laser from TRUMPF prints copper and gold, TRUMPF Glob. Press Release. (2018) 1-4. https://www.trumpf.com/en_INT/company/press/global-press-releases/press-release-detailpage/release/world-premiere-at-formnext-green-laser-from-trumpf-prints-copper-and-gold/.

[15] M. Lang, Formalloy Making New Wave(length)s in 3D Printing, Repair and Cladding, Additivemanufacturing.Com. (2017) 1. http://additivemanufacturing.com/2017/09/12/formalloy-making-new-wavelengths-in-3d- 
printing-repair-and-cladding/ (accessed March 27, 2019).

[16] H. Siva Prasad, F. Brueckner, J. Volpp, A.F.H. Kaplan, Laser metal deposition of copper on diverse metals using green laser sources, Int. J. Adv. Manuf. Technol. (2020). doi:10.1007/s00170-020-05117-z.

[17] M. Haubold, A. Ganser, T. Eder, M.F. Zäh, Laser welding of copper using a high power disc laser at green wavelength, Procedia CIRP. 74 (2018) 446-449. doi:10.1016/j.procir.2018.08.161.

[18] K. Asano, M. Tsukamoto, Y. Sechi, Y. Sato, S. Masuno, R. Higashino, T. Hara, M. Sengoku, M. Yoshida, Laser metal deposition of pure copper on stainless steel with blue and IR diode lasers, Opt. Laser Technol. 107 (2018) 291-296. doi:10.1016/j.optlastec.2018.06.012.

[19] S. Clijsters, T. Craeghs, S. Buls, K. Kempen, J.-P. Kruth, In situ quality control of the selective laser melting process using a high-speed, real-time melt pool monitoring system, Int. J. Adv. Manuf. Technol. 75 (2014) 1089-1101. doi:10.1007/s00170-014-6214-8.

[20] M. Markl, C. Körner, Multiscale Modeling of Powder Bed-Based Additive Manufacturing, Annu. Rev. Mater. Res. 46 (2016) 93-123. doi:10.1146/annurev-matsci-070115-032158.

[21] S.D. Jadhav, S. Dadbakhsh, L. Goossens, J.P. Kruth, J. Van Humbeeck, K. Vanmeensel, Influence of selective laser melting process parameters on texture evolution in pure copper, J. Mater. Process. Technol. 270 (2019) 47-58. doi:10.1016/j.jmatprotec.2019.02.022.

[22] T.-T. Ikeshoji, K. Nakamura, M. Yonehara, K. Imai, H. Kyogoku, Selective Laser Melting of Pure Copper, JOM. 70 (2018) 396-400. doi:10.1007/s11837-017-2695-x.

[23] M. Colopi, A.G. Demir, L. Caprio, B. Previtali, Limits and solutions in processing pure Cu via selective laser melting using a high-power single-mode fiber laser, Int. J. Adv. Manuf. Technol. (2019). doi:10.1007/s00170-019-04015-3.

[24] M. Sinico, G. Cogo, M. Benettoni, I. Calliari, A. Pepato, Influence of powder particle size distribution on the printability of pure copper for selective laser melting, in: 30th Annu. Int. Solid Free. Fabr. Symp., Solid Freeform Fabrication, Austin, Texas, USA, 2019: pp. 1-11.

[25] D. Tiberto, U.E. Klotz, F. Held, G. Wolf, Additive manufacturing of copper alloys: influence of process parameters and alloying elements, Mater. Sci. Technol. 35 (2019) 969-977. doi:10.1080/02670836.2019.1600840.

[26] S. Zhang, H. Zhu, L. Zhang, W. Zhang, H. Yang, X. Zeng, Microstructure and properties in QCr0.8 alloy produced by selective laser melting with different heat treatment, J. Alloys Compd. 800 (2019) 286-293. doi:10.1016/j.jallcom.2019.06.018.

[27] S. Zhang, H. Zhu, L. Zhang, W. Zhang, H. Yang, X. Zeng, Microstructure and properties of high strength and high conductivity $\mathrm{Cu}-\mathrm{Cr}$ alloy components fabricated by high power selective laser melting, Mater. Lett. 237 (2019) 306-309. doi:10.1016/j.matlet.2018.11.118.

[28] C. Wallis, B. Buchmayr, Effect of heat treatments on microstructure and properties of CuCrZr produced by laser-powder bed fusion, Mater. Sci. Eng. A. 744 (2019) 215-223. doi:10.1016/j.msea.2018.12.017.

[29] D. Palousek, M. Kocica, L. Pantelejev, L. Klakurkova, L. Celko, D. Koutny, J. Kaiser, SLM process parameters development of Cu-alloy Cu7.2Ni1.8Si1Cr, Rapid Prototyp. J. 25 (2019) 266-276. doi:10.1108/RPJ-06-2017-0116.

[30] S. Zhang, H. Zhu, Z. Hu, X. Zeng, F. Zhong, Selective Laser Melting of Cu 10Zn alloy powder using high laser power, Powder Technol. 342 (2019) 613-620.

doi:10.1016/j.powtec.2018.10.002.

[31] S.D. Jadhav, J. Vleugels, J. Kruth, J. Van Humbeeck, K. Vanmeensel, Mechanical and 
electrical properties of selective laser-melted parts produced from surface-oxidized copper powder, Mater. Des. Process. Commun. 2 (2020) 1-8. doi:10.1002/mdp2.94.

[32] S.D. Jadhav, P.P. Dhekne, S. Dadbakhsh, J.-P. Kruth, J. Van Humbeeck, K. Vanmeensel, Surface Modified Copper Alloy Powder for Reliable Laser-based Additive Manufacturing, Addit. Manuf. 35 (2020) 101418 (1-13). doi:10.1016/j.addma.2020.101418.

[33] A.H. Seltzman, S.J. Wukitch, RF losses in selective laser melted GRCop-84 copper waveguide for an additively manufactured lower hybrid current drive launcher, Fusion Eng. Des. 159 (2020) 111762. doi:10.1016/j.fusengdes.2020.111762.

[34] A.H. Seltzman, S.J. Wukitch, Surface roughness and finishing techniques in selective laser melted GRCop-84 copper for an additive manufactured lower hybrid current drive launcher, Fusion Eng. Des. 160 (2020) 111801. doi:10.1016/j.fusengdes.2020.111801.

[35] A.P. Ventura, C.A. Wade, G. Pawlikowski, M. Bayes, M. Watanabe, W.Z. Misiolek, Mechanical Properties and Microstructural Characterization of Cu-4.3 Pct Sn Fabricated by Selective Laser Melting, Metall. Mater. Trans. A. 48 (2017) 178-187. doi:10.1007/s11661016-3779-x.

[36] Z. Mao, D. Zhang, P. Wei, K. Zhang, Manufacturing Feasibility and Forming Properties of $\mathrm{Cu}-4 \mathrm{Sn}$ in Selective Laser Melting, Materials (Basel). 10 (2017) 333. doi:10.3390/ma10040333.

[37] S. Scudino, C. Unterdörfer, K.G. Prashanth, H. Attar, N. Ellendt, V. Uhlenwinkel, J. Eckert, Additive manufacturing of $\mathrm{Cu}-10 \mathrm{Sn}$ bronze, Mater. Lett. 156 (2015) 202-204. doi:10.1016/j.matlet.2015.05.076.

[38] Z. Mao, D.Z. Zhang, J. Jiang, G. Fu, P. Zhang, Processing optimisation, mechanical properties and microstructural evolution during selective laser melting of $\mathrm{Cu}-15 \mathrm{Sn}$ high-tin bronze, Mater. Sci. Eng. A. 721 (2018) 125-134. doi:10.1016/j.msea.2018.02.051.

[39] Jadhav, Dadbakhsh, Vleugels, Hofkens, Puyvelde, Yang, Kruth, Humbeeck, Vanmeensel, Influence of Carbon Nanoparticle Addition (and Impurities) on Selective Laser Melting of Pure Copper, Materials (Basel). 12 (2019) 2469(1-16). doi:10.3390/ma12152469.

[40] V.G. Mel'nikov, A.M. Kozlovskii, E.A. Nogovitsin, S. V Zvonov, Electroless tinning of copper powders, Sov. Powder Metall. Met. Ceram. 18 (1979) 73-75. doi:10.1007/BF00792073.

[41] S. Buls, A Smart Machine for Selective Laser Melting, KU Leuven, 2018. https://www.kuleuven.be/doctoraatsverdediging/fiches/3E11/3E110496.htm.

[42] S.J. Raab, R. Guschlbauer, M.A. Lodes, C. Körner, Thermal and Electrical Conductivity of 99.9\% Pure Copper Processed via Selective Electron Beam Melting, Adv. Eng. Mater. 18 (2016) 1661-1666. doi:10.1002/adem.201600078.

[43] A.J. Forsyth, S.R. Hutton, M.J. Rhodes, C.F. Osborne, Effect of applied interparticle force on the static and dynamic angles of repose of spherical granular material, Phys. Rev. E. 63 (2001) 031302. doi:10.1103/PhysRevE.63.031302.

[44] S. Dukarov, A. Kryshtal, V. Sukhov, Surface Energy and Wetting in Island Films, in: Wetting and Wettability, InTech, 2015: p. 13. doi:10.5772/60900.

[45] H. Udin, Grain Boundary Effect in Surface Tension Measurement, JOM. 3 (1951) 63-63. doi:10.1007/BF03398958.

[46] A.I. Golovashkin, G.P. Motulevich, Optical and electrical properties of tin, Sov. Phys. JETP. 19 (1964) 310-317. http://www.jetp.ac.ru/cgi-bin/dn/e_019_02_0310.pdf.

[47] D.R. Lide, W.M.M. Haynes, G. Baysinger, L.I. Berger, H. V Kehiaian, D.L. Roth, K. 
Kuchitsu, D. Zwillinger, M. Frenkel, R.N. Goldberg, CRC Handbook of Chemistry and Physics, CRC Press, Boca Raton, FL, 2005, 2005. doi:10.1021/ja906434c.

[48] D. Bergström, The Absorption of Laser Light by Rough Metal Surfaces, Luleå University of Technology, 2008.

[49] Y.H. Zhou, Z.H. Zhang, Y.P. Wang, G. Liu, S.Y. Zhou, Y.L. Li, J. Shen, M. Yan, Selective laser melting of typical metallic materials: An effective process prediction model developed by energy absorption and consumption analysis, Addit. Manuf. 25 (2019) 204-217.

doi:10.1016/j.addma.2018.10.046.

[50] T.-N. Le, Y.-L. Lo, Effects of sulfur concentration and Marangoni convection on melt-pool formation in transition mode of selective laser melting process, Mater. Des. 179 (2019) 107866. doi:10.1016/j.matdes.2019.107866.

[51] S. Sun, M. Brandt, M. Easton, Powder bed fusion processes: An overview, in: Laser Addit. Manuf., Elsevier, 2017: pp. 55-77. doi:10.1016/B978-0-08-100433-3.00002-6.

[52] C.R. Heiple, J.R. Roper, Mechanism for Minor Element Effect on Gta Fusion Zone Geometry, Weld. J. (Miami, Fla). 61 (1982) 97S-102S.

[53] C.F. Baes, H.H. Kellogg, Effect of Dissolved Sulphur on the Surface Tension of Liquid Copper, JOM. 5 (1953) 643-648. doi:10.1007/BF03397527.

[54] Z. Gan, G. Yu, X. He, S. Li, Surface-active element transport and its effect on liquid metal flow in laser-assisted additive manufacturing, Int. Commun. Heat Mass Transf. 86 (2017) 206214. doi:10.1016/j.icheatmasstransfer.2017.06.007.

[55] J. Trapp, A.M. Rubenchik, G. Guss, M.J. Matthews, In situ absorptivity measurements of metallic powders during laser powder-bed fusion additive manufacturing, Appl. Mater. Today. 9 (2017) 341-349. doi:10.1016/j.apmt.2017.08.006.

[56] J. Ye, S.A. Khairallah, A.M. Rubenchik, M.F. Crumb, G. Guss, J. Belak, M.J. Matthews, Energy Coupling Mechanisms and Scaling Behavior Associated with Laser Powder Bed Fusion Additive Manufacturing, Adv. Eng. Mater. 21 (2019) 1900185.

doi:https://doi.org/10.1002/adem.201900185.

[57] R. Cunningham, C. Zhao, N. Parab, C. Kantzos, J. Pauza, K. Fezzaa, T. Sun, A.D. Rollett, Keyhole threshold and morphology in laser melting revealed by ultrahigh-speed x-ray imaging, Science (80-. ). 363 (2019) 849-852. doi:10.1126/science.aav4687.

[58] D.L. Perry, Handbook of Inorganic Compounds, Second edi, CRC Press, Boca Raton, FL, 2011, 2011.

[59] H. Zhang, Y. Balaji, A. Nalin Mehta, M. Heyns, M. Caymax, I. Radu, W. Vandervorst, A. Delabie, Formation mechanism of 2D SnS 2 and $\mathrm{SnS}$ by chemical vapor deposition using $\mathrm{SnCl}$ 4 and H2S, J. Mater. Chem. C. 6 (2018) 6172-6178. doi:10.1039/C8TC01821A. 


\section{Supplementary Figures}

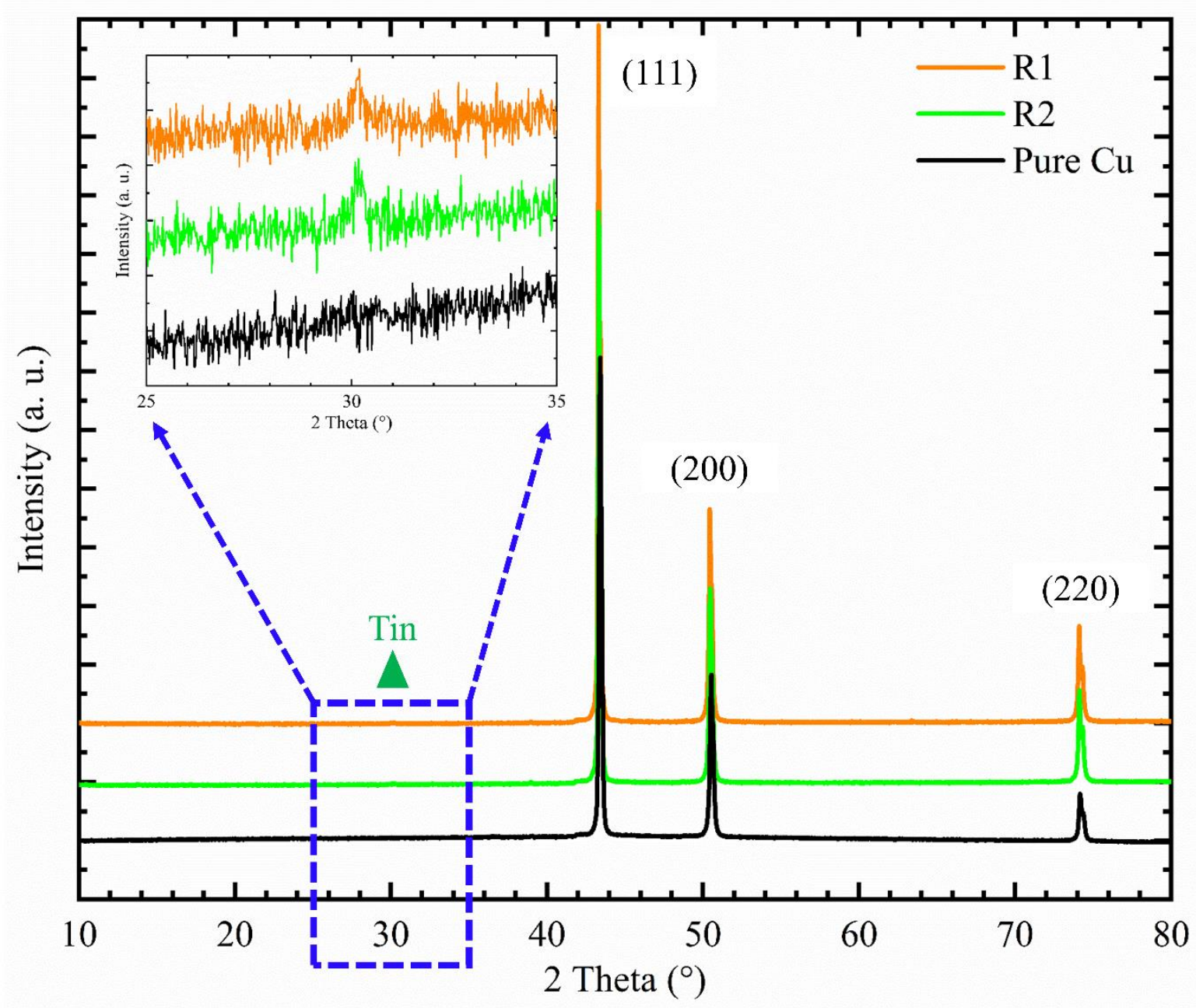

Supplementary Figure 1: X-ray diffraction spectra of the R1 and R2 powders along with a pure copper powder spectrum recorded before the tin coating. The inset of the figure shows the presence of a metallic tin peak for both tin-coated copper (R1 and R2) powders. 

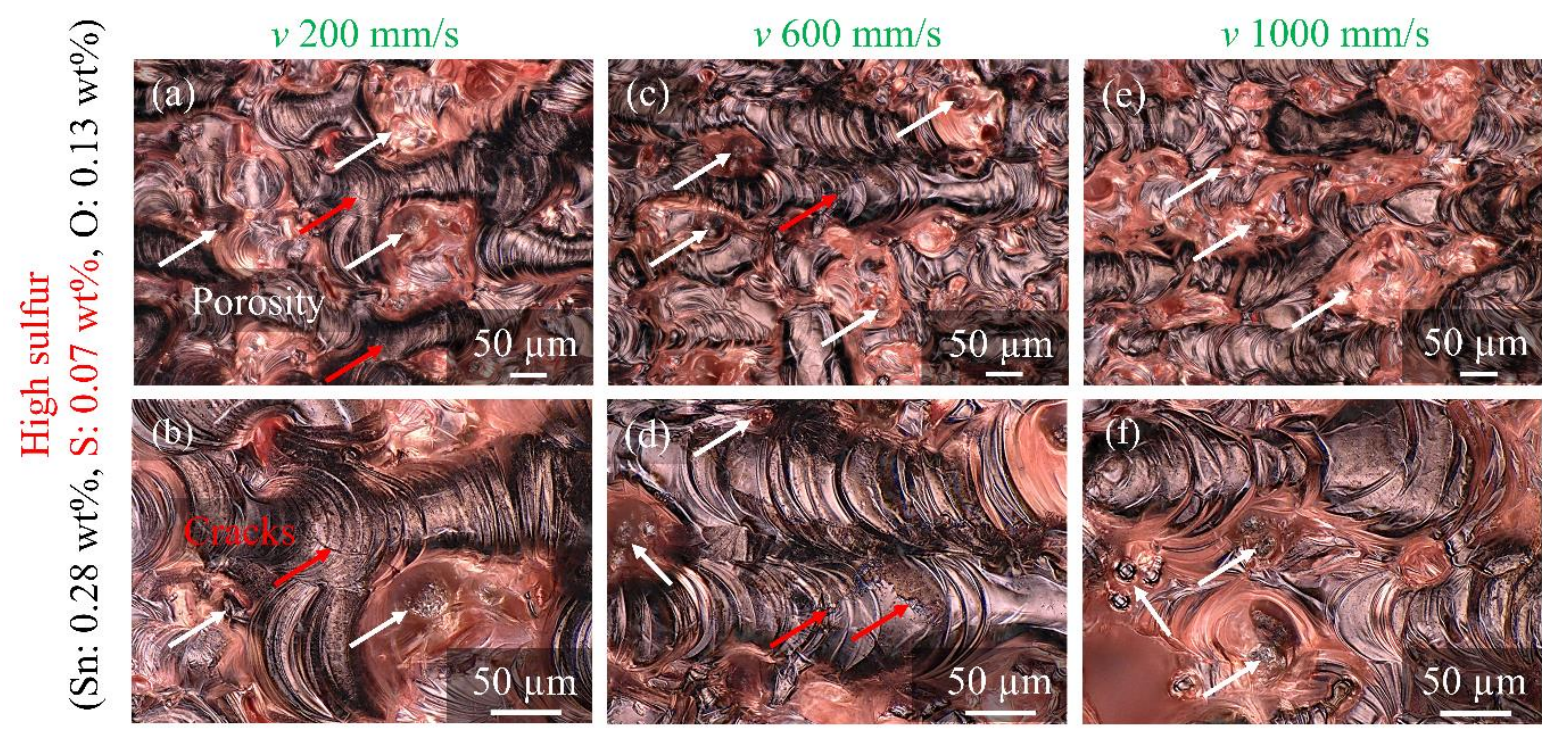

Supplementary Figure 2: Optical micrographs of the top surface of the parts produced using a fixed laser power $(P)$ of $500 \mathrm{~W}$, hatch spacing $(h)$ of $0.105 \mathrm{~mm}$, and different laser scan speeds $(v)$ of 200 , 600 , and $1000 \mathrm{~mm} / \mathrm{s}$. The parts were made of a tin-coated copper powder (labeled as R3) that exhibits the same tin content as the R2 powder, but a substantially higher sulfur content of $700 \mathrm{ppm}$. Despite having a similar powder optical absorption at the fiber laser wavelength and the same tin content of $0.28 \mathrm{wt} \%$, the LPBF processing behavior of the R3 powder is substantially different than the R2 powder, as depicted by the presence of cracks (red arrows), porosity (white arrows), and un-molten powder particles (white arrows) on the top surface of the samples. Notably, the R3 powder was produced using the same amount of coating organic additives as that of the R2 powder; however, the coating of the R3 powder was performed in an uncontrolled atmosphere (i.e. in the air) instead of the inert argon atmosphere, which was used during the production of the R2 powder. This indicates that the sulfur content has a very severe detrimental effect on the LPBF processing behavior of coppertin alloys, and the sulfur pickup during the tin coating process can be avoided by performing the tin coating experiments in an inert atmosphere, such as argon. 